INVESTIGACIONES

de HISTORIA ECONÓMICA

2007, invierno, número 7. Pp. 37 a 68

\title{
El poder de compra de jornaleros y criados. Salarios reales y mercados de trabajo en la Navarra rural, 1781-1936
}

\section{The purchasing power of labourers and servants. Real wages and labour markets in rural Navarre, 1781-1936}

\author{
JOSÉ MIGUEL LANA BERASAIN \\ Universidad Pública de Navarra
}

\begin{abstract}
RESUMEN
En este artículo se presentan nuevos cálculos del coste de la vida y de los salarios reales en la agricultura del sur de Navarra entre 1781 y

1936. La tipología de salarios que se maneja incluye a los trabajadores eventuales y a los permanentes, así como a hombres y a mujeres.

Los índices sugieren un aumento de la capacidad adquisitiva tras las guerras napoleónicas, un estancamiento y deterioro del nivel de vida durante la mayor parte del siglo XIX, y un nuevo incremento durante el primer tercio del siglo XX. Con todo, se advierten importantes diferencias dependiendo del segmento de mercado de trabajo de que se trate.
\end{abstract}

PALABRAS CLAVE: Niveles de vida, Índice de precios, Salarios reales, Mercados de trabajo,

Navarra, España contemporánea

Códigos JEL: I31, J31, J43, N33
ABSTRACT

This article presents new estimates of the cost of living and real wages in the agriculture from 1781 to 1936 in Southern Navarre. The typology of wages includes male labourers, female labourers and servants. The calculated indexes suggest that the rural standard of living increased after the Napoleonic Wars, stagnated and dropped along the 19th century, and rose again in the 20th century. Anyway, servants and labourers experienced remarkable differences in their living standard paths.

KEY WORDS: Living Standards, Price index, Real wages, Labour markets, Navarre, Contemporary Spain

JEL Codes: I31, J31, J43, N33 


\section{Preámbulo ${ }^{1}$}

$\mathrm{E}$ n los últimos años, el tema de la evolución de los niveles de vida en el mundo rural se ha ido convirtiendo en un fecundo campo de trabajo de la historiografía económica española. Fecundo no tanto desde el punto de vista de la cantidad de aportaciones, que aún hoy es muy limitada, sino desde la perspectiva de su variedad y de su rigor. El campo de observación se ha abierto a enfoques y metodologías muy diversas, aunque complementarias: junto a los más o menos convencionales estudios sobre salarios reales, en realidad muy pocos, encontramos cada vez en mayor número trabajos antropométricos a partir de tallas de reclutas, análisis demográficos sobre mortalidad infantil y esperanza de vida, estudios sobre educación y escolarización, trabajo infantil o pauperismo, o reconstrucciones de la situación material a partir de inventarios de bienes y escrituras dotales. Lo que todos estos novedosos enfoques presentan en común es su aproximación a partir de los resultados, y no tanto de los condicionantes del nivel de vida. Desde esta última perspectiva, los salarios nominales y el coste de la vida continúan siendo los referentes indiscutibles, aunque no faltan otros esfuerzos más imaginativos para situar las condiciones de reproducción de las familias campesinas².

El amplio predominio de la figura del jornalero en los siglos XIX y XX, así como la idoneidad del jornal a la hora de sintetizar la remuneración típica de la fuerza de trabajo, junto a otros factores de naturaleza metodológica, como el propio acceso a las fuentes, han hecho que los estudios sobre el nivel de vida desde la perspectiva del salario real hayan tendido a fijarse únicamente en ese segmento del mercado de

[Fecha de recepción del original, abril de 2006. Versión definitiva, septiembre de 2006]

1 Este artículo es una versión corregida y ampliada de una comunicación presentada al VIII Congreso de la Asociación Española de Historia Económica (Santiago de Compostela, 13-16 septiembre 2005). Se inscribe dentro del proyecto de investigación $\mathrm{S} 3100007 \mathrm{H}$, “Navarra en el crecimiento económico de la Europa de las regiones, siglos XIX y XX", financiado por el Gobierno de Navarra. El autor está en deuda con los profesores Eduardo Sánchez Iriso, Joseba de la Torre, Gloria Sanz Lafuente y José Miguel Gastón, así como con los autores de los tres informes de evaluación de Investigaciones de Historia Económica. Mi gratitud se extiende también a los archivos consultados, en especial a las familias Sanz-Magallón y Silva-Azlor, así como a la Casa de Misericordia de Pamplona y a su archivera Beatriz Itoiz. La exclusiva responsabilidad del texto y de sus deficiencias es del autor.

2 Los hitos más destacados de la irrupción en España del debate sobre los niveles de vida son el XV Simposio de Análisis Económico (Barcelona, 1990), el VII Congreso de Historia Agraria (Salamanca, 1997) y el VIII Congreso de la Asociación Española de Historia Económica (Santiago de Compostela, 2005). La obra de referencia es, sin duda, el volumen coordinado por Martínez Carrión (2002), en el que se hallará una buena muestra de la diversidad de enfoques a la que he aludido. Particularmente imaginativo resulta el trabajo de Colomé, Saguer y Vicedo (2002), en la línea de las pioneras aportaciones de Garrabou (1987) y Garrabou y Tello (2002). Una interesante combinación de salarios reales e indicadores complementarios de tipo antropométrico y demográfico, en Pérez Castroviejo (2006) y Moreno (2006). Perspectivas globales del problema pueden hallarse en Engerman (1994) y, más recientemente, en Allen, Bengtsson y Dribe (2005). 
trabajo, omitiendo otras posibles formas de contratación y remuneración, como pudieran ser las figuras de los criados y criadas, o los contratos de destajo. Precisamente es éste, el de la configuración y evolución de los mercados de trabajo, otro campo de estudio que está recibiendo una creciente atención y que promete fecundos resultados. Sobre el sustrato de los estudios de corte sociológico que concentraban su atención sobre la dicotomía jornalero/campesino, han ido apareciendo otras propuestas con un contenido más demográfico y antropológico, que arrojan luz sobre la lógica del segmento de mercado integrado por criadas y criados ${ }^{3}$.

Este trabajo pretende, con una concepción amplia de los mercados de trabajo, aportar algunos elementos al debate sobre los niveles de vida desde la perspectiva del salario real. Dicho de otra forma, lo que se quiere averiguar es si el desarrollo del capitalismo en la agricultura entre finales del siglo XVIII y el primer tercio del XX mejoró o deterioró la capacidad adquisitiva de los trabajadores rurales. No es que el salario sea necesariamente el principal dato, ni mucho menos el único, que determine el nivel de vida, pero sí que es cierto que se trata de una variable muy relevante en aquellas regiones con amplia presencia de proletariado agrícola. Como ya se ha advertido, se entiende que la respuesta a este interrogante requiere tomar en consideración no sólo la remuneración de los jornaleros o trabajadores eventuales, sino también la realidad de los asalariados con un mayor grado de permanencia y estabilidad en el empleo. El espacio geográfico al que se circunscribe este artículo es la Navarra meridional, una zona con rasgos homogéneos en la que las estructuras de propiedad de la tierra y de la propiedad urbana condicionaban la existencia de un amplio segmento de población dependiente del salario para su supervivencia y abocada al inquilinato como medio de acceso a la vivienda.

Las fuentes empleadas para este empeño han sido los libros de cuentas de dos linajes, unas pocas familias, cuatro monasterios y dos instituciones civiles dedicadas a la beneficencia y a los abastos. El eje sobre el que descansan las series de precios y salarios lo constituyen los archivos particulares de los marqueses de San Adrián (1793-1900) y de los duques de Miranda (1862-1936). Para la elaboración de los índices de precios ha resultado insustituible la documentación de la Casa y Fábrica de Tejidos de la Misericordia de Pamplona, así como del Ramo de Carnicerías de la misma ciudad. El resto de los fondos manejados tienen un carácter fragmentario aunque permiten completar y contrastar la información recogida.

3 No por casualidad, los trabajos que estudian el mercado de trabajo desde la perspectiva de los jornaleros se localizan en Andalucía (Garrido, 1997; Florencio y López, 2000 y 2003), mientras que es en el norte donde tiende a ponerse el acento sobre los trabajadores estables (Saguer, 2004; Dubert, 2005; Roca, 2005). En los números 25 y 35 de Historia Agraria pueden hallarse algunos trabajos referidos al sur de Italia, Cerdeña, Suecia y Holanda. 
En las páginas siguientes se presentarán un conjunto de series numéricas que nos permitirán abordar este asunto con ciertas garantías. En primer lugar, se presentarán algunas series de precios de bienes de consumo con el fin de proponer un índice del coste de la vida para Navarra en el período 1782-1905. A continuación, se abordarán las peculiaridades de los mercados de trabajo y se presentarán las series elaboradas para jornales y salarios de trabajadores eventuales y fijos. Por último, cruzando estas series, se realizará una aproximación a la evolución de la capacidad adquisitiva de estas remuneraciones.

\section{Bienes de consumo y coste de la vida}

Resulta extraordinariamente difícil determinar las pautas de consumo de la población rural del período que nos ocupa, ya que las informaciones directas y completas son muy escasas. Referidas a Navarra, tan sólo contamos con tres noticias de muy distinta calidad: una cesta típica manejada por el marqués de San Adrián en una obra de 1780, una sucinta y confusa estimación remitida por la Junta provincial de Agricultura, Industria y Comercio en 1849 al Ministerio de Fomento, y un conjunto de detallados cálculos elaborados municipio a municipio por técnicos de la sección del Catastro de la Diputación Foral para las cartillas evaluatorias de 1903-19064.

A pesar de tan pobre punto de partida, podemos hallar consuelo y apoyo en la literatura sobre el tema. Por un lado, las grandes líneas de las pautas de consumo anteriores al siglo XX parecen coincidir aún en economías tan disímiles como la española y la británica. El Cuadro 1 resume algunas ponderaciones utilizadas por diferentes autores en estudios sobre coste de la vida y salarios reales que permiten comprobar la relativamente homogénea distribución del gasto familiar típico en sus grandes apartados de alimentación, vivienda, indumentaria y combustibles. Para el primero de esos renglones, la mayor parte de los autores se mueven en torno a una proporción del 70 por 100 del gasto, aunque su composición en el detalle es muy diversa como consecuencia de pautas locales de producción y de culturas de consumo muy variadas. Por lo que se refiere a la vivienda, aquellos autores que la recogen le atribuyen un porcentaje situado en torno al 10-13 por 100. Una proporción parecida, entre el 8 y el 12 por 100, se asigna al capítulo de vestido y calzado, mientras que el combustible varía desde un 4 hasta un 15 por 100. El capítulo de alumbrado recibe una atención específica en las series inglesas, que lo sitúan entre el 1 y el 4 por 100. 


\section{CUADRO 1}

PRESUPUESTOS FAMILIARES MANEJADOS POR DIVERSOS AUTORES

EN SUS ÍNDICES DE COSTE DE LA VIDA

(porcentajes sobre el total de gasto)

\begin{tabular}{|c|c|c|c|c|c|c|c|c|c|c|}
\hline \multirow{2}{*}{$\begin{array}{l}\text { Partidas } \\
\text { de gasto }\end{array}$} & \multicolumn{5}{|c|}{ España } & \multicolumn{2}{|c|}{ Inglaterra } & \multicolumn{2}{|c|}{ Inglaterra rural } & \multirow{2}{*}{$\frac{\text { Irlanda }}{(10)}$} \\
\hline & (1) & (2) & (3) & (4) & (5) & (6) & (7) & (8) & (9) & \\
\hline Alimentación & 75,00 & 70,00 & 83,50 & 65,00 & 70,00 & 69,00 & 61,00 & 77,00 & 69,60 & 67,40 \\
\hline Pan & 0,00 & 21,00 & 0,00 & 0,00 & 44,00 & 13,80 & 18,30 & 0,00 & 0,00 & 14,50 \\
\hline Harina & 0,00 & 0,00 & 0,00 & 0,00 & 5,00 & 18,60 & 9,10 & 0,00 & 0,00 & 0,00 \\
\hline Trigo & 37,50 & 0,00 & 32,40 & 27,30 & 0,00 & 0,00 & 0,00 & 38,10 & 37,40 & 0,00 \\
\hline Centeno & 0,00 & 0,00 & 5,40 & 0,00 & 0,00 & 0,00 & 0,00 & 0,00 & 0,00 & 0,00 \\
\hline Maíz & 0,00 & 0,00 & 3,90 & 0,00 & 0,00 & 0,00 & 0,00 & 0,00 & 0,00 & 0,00 \\
\hline Cebada & 0,00 & 0,00 & 0,00 & 0,00 & 0,00 & 0,00 & 0,00 & 2,40 & 1,40 & 0,00 \\
\hline Avena & 0,00 & 0,00 & 0,00 & 0,00 & 0,00 & 9,00 & 1,80 & 7,10 & 2,80 & 12,30 \\
\hline Legumbres & 11,25 & 8,75 & 7,50 & 4,60 & 5,00 & 0,00 & 0,00 & 0,00 & 0,00 & 0,00 \\
\hline Arroz & 3,75 & 1,75 & 1,10 & 0,00 & 0,00 & 0,00 & 0,00 & 0,00 & 0,00 & 0,00 \\
\hline Patatas & 0,00 & 14,00 & 2,00 & 0,00 & 0,00 & 3,40 & 6,10 & 0,00 & 6,20 & 8,80 \\
\hline Carne & 3,75 & 7,00 & 10,90 & 10,40 & 1,00 & 4,20 & 5,50 & 9,40 & 3,50 & 4,00 \\
\hline Pescado & 0,00 & 3,50 & 1,40 & 0,00 & 1,00 & 0,00 & 0,00 & * & * & 3,30 \\
\hline Tocino & 7,50 & 0,00 & 1,40 & 0,00 & 5,00 & 4,80 & 4,90 & 1,30 & 2,90 & 0,00 \\
\hline Leche & 0,00 & 2,10 & 0,00 & 0,00 & 0,00 & 3,40 & 4,30 & 4,10 & 3,30 & 11,50 \\
\hline Huevos & 0,00 & 2,10 & 0,00 & 3,20 & 2,00 & 0,00 & 0,00 & 0,00 & 0,00 & 0,00 \\
\hline Queso & 0,00 & 0,00 & 0,00 & 0,00 & 2,00 & 2,10 & 1,80 & 3,60 & 2,70 & 0,00 \\
\hline Mantequilla & 0,00 & 0,00 & 0 , & 0,00 & 1,00 & 2,80 & 3,00 &, 00 & 3,40 &, 00 \\
\hline Aceite & 2,25 & 3,50 & 6,60 & 10,40 & 0,00 & 0,00 & 0,00 & 0,00 & 0,00 & 0,00 \\
\hline Sal & 0,00 & 0,00 & 0,00 & 0,00 & 0,00 & 0,00 & 0,00 & 0,00 & 0,00 & 0,40 \\
\hline Azúcar & 0,00 & 1,40 & 1,00 & 0,00 & 0,00 & 4,80 & 4,30 & 3,70 & 3,20 & 4,50 \\
\hline Te y café & 0,00 & 1,40 & 0,00 & 0,00 & 0,00 & 2,10 & 1,80 & 2,40 & 2,70 & ** \\
\hline Vino & 5,25 & 3,50 & 9,90 & 9,10 & 2,00 & 0,00 & 0,00 & 0,00 & 0,00 & 0,00 \\
\hline Cerveza & 0,00 & 0,00 & 0,00 & 0,00 & 0,00 & 10,00 & 12,00 & 1,00 & 0,00 & 0,00 \\
\hline Aguardiente & 3,75 & 0,00 & 0,00 & 0,00 & 0,00 & 0,00 & 0,00 & 0,00 & 0,00 & 8,70 \\
\hline Vivienda & 0,00 & 10,00 & 0,0 & 15,00 & 0,00 & 10,00 & 13,00 & 6,00 & 10,10 & 12,60 \\
\hline Combustible & 12,50 & 5,00 & 8,30 & 6,00 & 15,00 & 4,00 & 4,00 & 4,00 & 4,50 & 6,20 \\
\hline Alumbrado & 0,00 & 0,00 & 0,00 & 0,00 & 0,00 & 1,00 & 1,00 & 4,80 & 3,30 & 1,20 \\
\hline Jabón & 0,00 & 5,00 & 0,00 & 1,50 & 0,00 & 0,00 & 0,00 & $* * *$ & $* * *$ & 2,10 \\
\hline Tabaco & 0,00 & 0,00 & 0,00 & 0,00 & 0,00 & 0,00 & 0,00 & 0,00 & 0,00 & 2,90 \\
\hline Vestido-calzado & 12,50 & 10,00 & 8,00 & 12,50 & 15,00 & 6,00 & 9,00 & 8,20 & 11,70 & 7,90 \\
\hline Servicios & 0,00 & 0,00 & 0,00 & 0,00 & 0,00 & 0,00 & 0,00 & 0,10 & 0,70 & 0,00 \\
\hline
\end{tabular}


(1) Estimación de Ballesteros para España (1860-1890).

(2) Estimación de Ballesteros para España (1907-1936).

(3) Estimación de Barquín para el conjunto español a partir de los derechos de puertas y consumo (1815-1860).

(4) Índice de coste de la vida de Castilla la Vieja elaborado por Moreno (1850-1853).

(5) Estimación de Martínez Vara para Santander (1851-1860).

(6) Estimación de Feinstein para los trabajadores ingleses (1788-1792).

(7) Estimación de Feinstein para los trabajadores ingleses (1858-1862).

(8) Estimación de Clark para los trabajadores rurales ingleses (1670-1819).

(9) Estimación de Clark para los trabajadores rurales ingleses (1820-1869).

(10) Cesta de consumo de Geary y Stark para Irlanda (1835-36).

* Carne y pescado.

** Té y azúcar juntos.

*** Jabón incluido en Alumbrado.

Fuentes: Ballesteros (1997), pp. 368-373; Barquín (2001), p. 308; Moreno (2002), p. 81; Martínez Vara (1997); Feinstein (1998); Clark (2001), p. 493, y Geary y Stark (2004), p. 365.

No ocurre lo mismo en las ponderaciones españolas, aunque aquí debería tenerse en cuenta que una parte de la proporción ocupada por el aceite, incluido en el capítulo de alimentación, debería corresponder a su uso para iluminación ${ }^{5}$.

Con base en los criterios manejados por estos autores y en la información de época citada más arriba, propondré una canasta de consumo para la Navarra del lapso 1781-1905. En el Cuadro 2 se ofrecen de nuevo algunos de estos datos agrupados en seis grandes capítulos. Apoyándome en las respuestas de las juntas provinciales de Navarra y Logroño al interrogatorio de Fomento adoptaré como criterio un gasto en vivienda del 10 por 100 y en limpieza del 1,5 por 100. Son estas partidas las que están ausentes en la estimación que realiza Barquín de las pautas de consumo en la España del Ochocientos a partir de los derechos cobrados por impuestos de puertas y de consumos. El trabajo de este autor proporciona, sin duda, una aproximación más sólida a la estructura del consumo que la que permiten unas pocas encuestas de época, respondidas a menudo con escaso interés. Por ello, se toma como pauta para estimar las proporciones de los demás capítulos, reajustando los coeficientes a fin de dar entrada a los renglones de vivienda y limpieza. El resultado final asigna un 74,5 por 100 a alimentación, un 10 por 100 a vivienda, un 7 por 100 a calefacción, otro 7 por 100 a indumentaria y un 1,5 por 100 a limpieza ${ }^{6}$.

5 Puede encontrarse una completa recopilación de presupuestos familiares manejados en la literatura internacional sobre niveles de vida, en Hoffman, Jacks, Levin y Lindert (2005), pp. 140-144. En la mayor parte de los mismos, el gasto en alimentación rondaría el 70 por 100, salvo en el caso de las clases sociales de alta renta (nobleza, burguesía), en las que oscilaría entre el 25 y el 40 por 100.

6 El gasto en vivienda viene representado por el alquiler medio de las casas de calidad media-baja; el de calefacción, por el precio del carbón vegetal; el de limpieza, por el jabón; el de indumentaria, por una ponderación de los precios de los paños comunes, las mantas, las alpargatas y la suela de calzado. Una aclaración más extensa de las características de estas series, así como de la metodología empleada, en Lana (2005). 


\section{CUADRO 2}

DISTRIBUCIÓN DEL PRESUPUESTO FAMILIAR DE GASTO SEGÚN DISTINTOS AUTORES

Y PROPUESTA PROPIA PARA NAVARRA, 1783-1905

(porcentajes sobre el total de gasto)

\begin{tabular}{lrrrrrrrrr}
\hline Partidas de gasto & $\mathbf{( 1 )}$ & $\mathbf{( 2 )}$ & $\mathbf{( 3 )}$ & $\mathbf{( 4 )}$ & $\mathbf{( 5 )}$ & $\mathbf{( 6 )}$ & $\mathbf{( 7 )}$ & $\mathbf{( 8 )}$ & $\mathbf{( 9 )}$ \\
\hline Alimentación & 68,0 & 70,9 & 63,2 & 83,5 & 65,0 & 70,0 & 69,4 & 70,0 & 74,5 \\
Vivienda & 7,8 & 11,6 & 14,0 & 0,0 & 15,0 & 13,0 & 10,8 & 10,0 & 10,0 \\
Calefacción & 4,1 & 0,0 & 11,7 & 8,3 & 6,0 & 6,0 & $6,2^{*}$ & 5,0 & 7,0 \\
Limpieza & 0,0 & 0,0 & 1,7 & 0,0 & 1,5 & 4,0 & - & 5,0 & 1,5 \\
Indumentaria & 20,0 & 14,6 & 9,4 & 8,0 & 12,5 & 7,0 & 10,3 & 10,0 & 7,0 \\
Servicios & 0,0 & 2,9 & 0,0 & 0,0 & 0,0 & 0,0 & $3,3^{* *}$ & 0,0 & 0,0 \\
Total & 99,9 & 100,0 & 100,0 & 99,8 & 100,0 & 100,0 & 100,0 & 100,0 & 100,0 \\
\hline
\end{tabular}

(1) Estimación del marqués de San Adrián para una familia de cinco miembros (1780).

(2) Estimación de la Junta provincial de Agricultura, Industria y Comercio de Navarra (1849).

(3) Estimación de la Junta provincial de Agricultura, Industria y Comercio de Logroño (en vivienda se incluye el mobiliario y menaje) (1852).

(4) Estructura del consumo estimada a partir de los derechos de puertas y consumos (1815-1860).

(5) Índice del coste de la vida en Palencia (1850-1853).

(6) Índice del coste de la vida en la zona industrial de Vizcaya (1876-1905).

(7) Estructura de consumo de las familias en España hacia 1830.

(8) Estimación de Ballesteros para España (1907-1936).

(9) Propuesta del autor para Navarra (1783-1905).

* Gastos de casa.

** Gastos diversos.

Fuentes: Astigarraga (1996); Del Moral (1979); Barquín (2001); Moreno (2002); Pérez Castroviejo (2006), p. 109; Maluquer (2005), p. 1.257, y Ballesteros (1997).

Estas proporciones se mantienen inmóviles entre 1783 y 1905, ya que no disponemos de informaciones más precisas que nos permitan ajustar las transformaciones experimentadas en la estructura de consumo. Lo que sí se ha modificado es la composición interna del capítulo alimenticio, para dar entrada desde 1850 a cultivos nuevos como la patata, o a productos ultramarinos cuyo consumo se difundió durante el siglo XIX, como el azúcar o el chocolate. Así pues, el índice de precios que manejaremos utilizará tres cestas diferentes con cortes cronológicos en 1850 y en 1905, aunque en todas ellas el capítulo de alimentación continuará ocupando un lugar preponderante. En todo caso, se trata de un índice provisional, a la espera de poder reconstruir mejor los cambios en el consumo y de incorporar los servicios (educativos, sanitarios, espirituales, recreativos, etc.), como lo hace Clark para la Inglaterra rural ${ }^{7}$.

7 La cesta manejada entre 1782 y 1849 concede un 37,7 por 100 del gasto total al trigo, 6,9 a las alubias, 2,1 al arroz, 8,2 a la carne de vaca, 2,1 al abadejo, 1,4 a la sal, 10,3 al vino y 6 al aceite de oliva. El período 1850-1905 incorpora las patatas con un 5,5 por 100, el azúcar con un 1,4, y el chocolate con un 0,7 , y sitúa las proporciones del trigo en un 28,8 por 100 , las alubias en un 6,2 y el arroz en un 4,1. Las proporciones de los demás artículos no varían. 
Un aspecto igualmente delicado es el de la elección de los precios. Son muy conocidos los argumentos a favor o en contra del uso de precios al por mayor, de precios al detalle o de precios institucionales. Estos últimos presentan el inconveniente de que no siempre reflejan precios de mercado, ya que la escala de las compras, las exenciones fiscales o la naturaleza de los contratos firmados por instituciones benéficas y entidades públicas pueden sesgar la representatividad de esos precios. En este trabajo se han utilizado principalmente precios de venta de productores, habitualmente a mayoristas, aunque también al detalle, para los casos del trigo, vino, aceite, alubias, carne de vacuno y textiles. Se trata por tanto de precios que no incorporan los tributos indirectos y que por ello no coinciden con los precios de compra para el consumidor. Para el resto de las mercancías manejadas (arroz, patatas, bacalao, sal, azúcar, chocolate, jabón, combustible y calzado) se han empleado precios de compra de corporaciones eclesiásticas (monasterios de Fitero y La Oliva) y de beneficencia (Casa de Misericordia de Pamplona). Pese a las tradicionales reservas frente a este tipo de precios, se puede defender que los efectos de un eventual sesgo sobre el índice de precios son, en todo caso, menores, debido, en primer lugar, a que afectan a productos poco importantes dentro de la cesta y, en segundo lugar, a que estas series reflejan igualmente bien las fluctuaciones y tendencias generales. Una particularidad añadida de todos estos precios es que vienen referidos, no al año natural ni al año agrícola, sino al año contable.

Hechas estas aclaraciones estoy en condiciones de presentar la serie de coste de la vida en Navarra durante el período 1782-1905. Se trata de un índice de Laspeyres que toma como base 100 el decenio 1891-1900. El Gráfico 1 refleja la evolución del índice entre 1782 y 1905, y permite contrastar su recorrido con el de las series provinciales construidas por Ballesteros, así como con la serie larga de precios del trigo en el sur de Navarra entre 1782 y 1936.

La primera idea que sugiere el gráfico es que el nuevo índice valida los elaborados por Ballesteros para Navarra, referidos a 1861-1890 y 1907-1936, el segundo de los cuales será utilizado para prolongar la serie que aquí se presenta ${ }^{8}$. Por otra parte, como no podía ser menos, el índice sigue en gran medida el trazado de la serie de precios del trigo, si bien la suaviza notablemente al eliminar las fluctuaciones más violentas. En tercer lugar, la serie muestra entre 1782 y 1850 un carácter cíclico mucho más acusado que en la segunda mitad del siglo, reduciéndose los coeficientes de variación de 25,9 a 12,1 por 100. Asentado, pues, el sistema capitalista a mediados del Ochocientos, se consolidó un escenario de precios estables desde 1860, espe-

$8 \quad$ Ballesteros (1997) construyó dos series para Navarra: una con base 1862-1864 para el lapso 1861-1890 y otra con base 1913 para el lapso 1907-1936. Utilizando como referencia la serie española de la misma autora, reduje ambas a una base 100 común en 1891-1900. Es ésta la que se recoge en el Gráfico 1. 


\section{GRÁFICO 1}

ÍNDICES DE PRECIOS EN NAVARRA, 1782-1936

(base $100=1891-1900)$

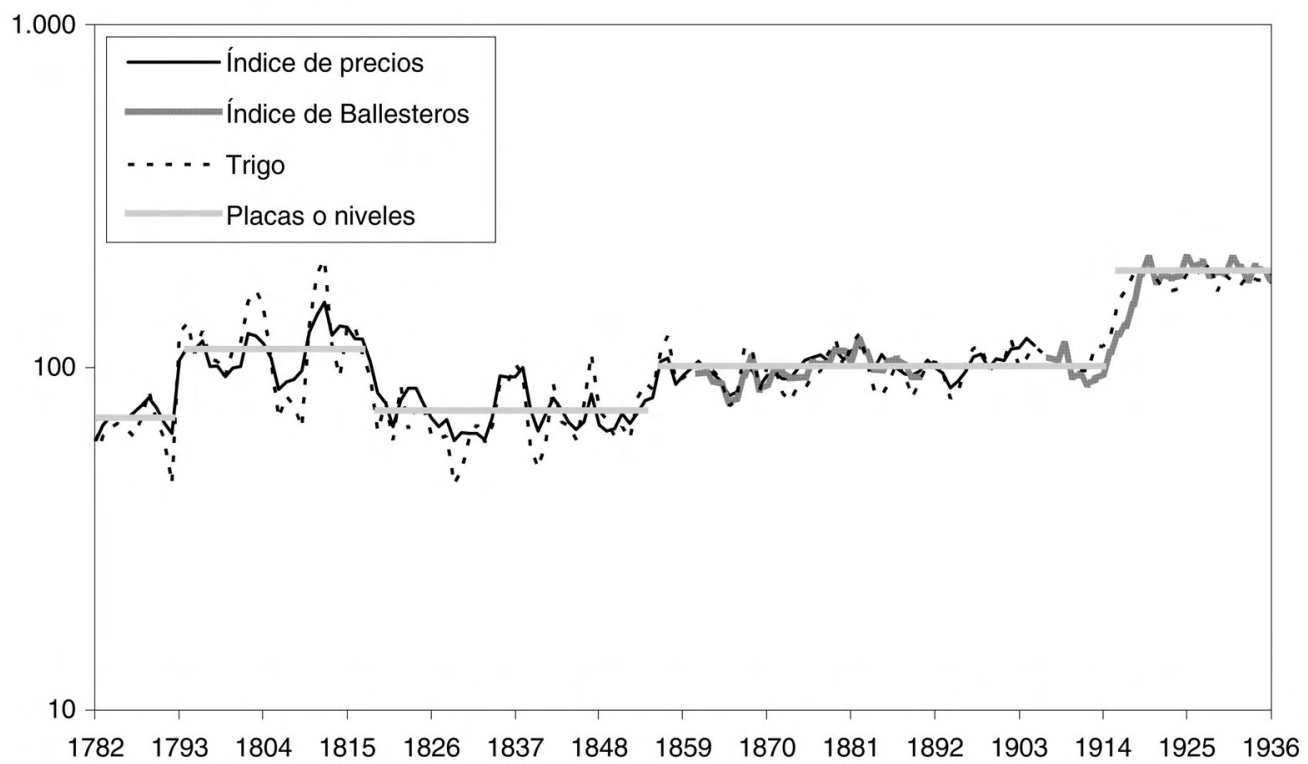

Fuentes: Fuentes manuscritas y Ballesteros (1997).

cialmente, hasta 1913. Por último, las tendencias seguidas por los precios pueden ser vistas como una sucesión de placas colocadas a diferente altura en cuyo seno, al margen de ciclos y fluctuaciones de mayor o menor calibre, se adivina una continuidad de nivel. Así, entre 1793 y 1818 se dibuja una placa de precios altos sobre la trayectoria de la penúltima década del siglo XVIII, aunque se perciben también dos ciclos depresivos en torno a 1799 y 1806. Tras la deflación postnapoleónica podemos trazar una placa de precios bajos entre 1819 y 1855, rota tan sólo por carestías ocasionadas por guerras civiles (1822-1824 y 1835-1838) y malas cosechas (1842 y 1847). Entre 1856 y 1915 discurre la citada línea de precios estables a un nivel más elevado que la anterior, con algunas depresiones cíclicas en torno a 1865, 1894 y 1910, que, tras el escalón provocado por la Gran Guerra, da paso a un nuevo escenario de precios que prácticamente dobla el nivel anterior. Dicho de otra manera, el índice marca tres grandes rupturas inflacionarias coincidiendo con la guerra contra la Convención Francesa, el Bienio Progresista y la I Guerra Mundial, y una gran ruptura deflacionaria tras la derrota de Napoleón. Más allá de estos momentos cruciales, se perciben movimientos del índice al alza o a la baja, de naturaleza cíclica y carácter coyuntural. 


\section{Las remuneraciones de la fuerza de trabajo}

Construir series homogéneas de ingresos salariales presenta sus propias particularidades. Como es sabido, a partir de registros contables no es difícil elaborar series de jornales para las diferentes tareas agrícolas, y es factible proponer un índice sintético para el tipo de remuneración más habitual en el campo entre 1785 y 1936: la del bracero poco especializado contratado por días. Sin embargo, antes de presentar las series salariales, convendrá desentrañar qué hay detrás de esa cifra, qué es lo que ésta expresa.

En la determinación del jornal intervienen cuatro variables que pueden expresarse del siguiente modo:

$$
J=w \cdot f \cdot g \cdot h
$$

Donde $J$ es la cotización del jornal (a estos efectos es irrelevante que su expresión sea en dinero o en especie); $w$ es el precio de la fuerza de trabajo referido a una unidad de tiempo básica y homogénea (pongamos la hora); $f$ es un factor multiplicador relacionado con el capital humano, o dicho de otra manera, con la cualificación del trabajador (su valor sería por tanto cercano a 1 en el caso de tareas que no requerían especial cualificación); $g$ es un coeficiente neutro para el caso del varón adulto (su valor sería igual a 1), pero que actúa como coeficiente reductor para aquellos grupos de trabajadores constituidos en reserva de fuerza de trabajo, cuya capacidad de negociación era inferior debido a razones de subordinación social expresadas en las variables de edad y género 9 ; $h$, finalmente, representa la magnitud temporal (el número de horas) de la jornada de trabajo.

Así pues, en el caso de que $f$ y $g$ sean iguales a uno, hecho bastante frecuente en las contabilidades que uno puede manejar, la homogeneidad del índice de salario nominal tan sólo deberá preocuparse por el valor de $h$, es decir, por la duración horaria de la jornada de trabajo. Para el caso que nos ocupa, conocemos por diversas fuentes que la misma en el sur de Navarra se situaba en torno a las ocho horas, salvo

9 A no ser que se considere, como llega a insinuar Burnette (2004), que la inferior remuneración de las mujeres tiene que ver con una productividad inferior a la de los hombres para las tareas agrícolas. Creo firmemente que la causa del diferencial de género en los salarios agrícolas ha de buscarse en el hecho de que el trabajo de mujeres y niños en un sistema patriarcal cumple la función de reserva de fuerza de trabajo movilizable en circunstancias excepcionales, por ejemplo, en un contexto de alzas salariales del trabajador varón adulto. Al menos en el sur de Navarra, ese diferencial tendió a recortarse, pese a registrar fuertes fluctuaciones en el corto y medio plazo: si en 1800-1820 la ratio era 0,416, en 1840-1860 ascendía a 0,456, en 18801900, a 0,465, y en 1904-1923, a 0,510. ¿Es que aumentó la productividad de la fuerza de trabajo femenina más que la masculina o es que se fue modificando su papel en la sociedad y su capacidad de negociación? Esto último me parece más convincente. 


\section{GRÁFICO 2}

EVOLUCIÓN DEL JORNAL DIARIO MASCULINO Y FEMENINO EN EL SUR DE NAVARRA, 1781-1936 (pesetas corrientes)

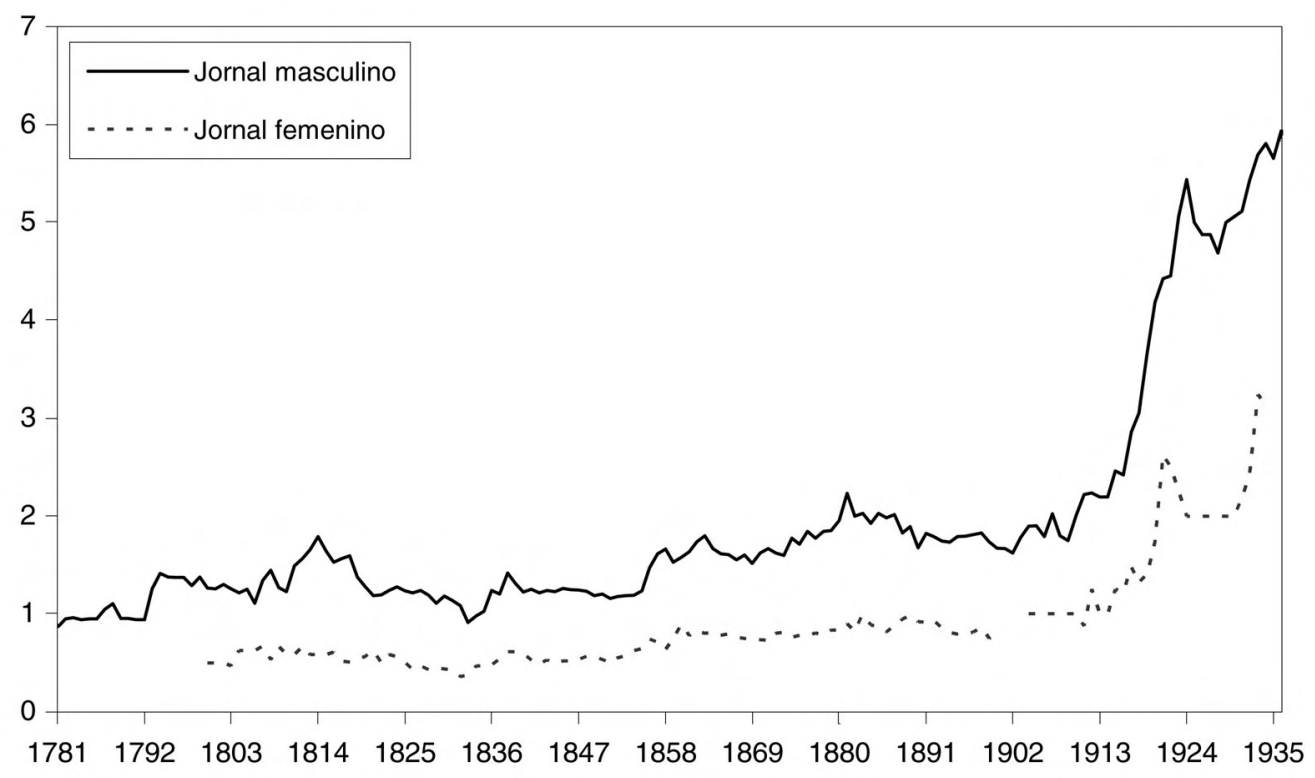

Fuentes: Archivo General de Navarra (AGN, en adelante), Clero, Fitero, libro 458; La Oliva, libro 533; Tulebras, libro 324; Papeles sueltos, caja 34.084. AGN, Arteta, cajas 13-15; Baronía de La Torre, cajas 1, 12, 24 y 26. Archivo de los Marqueses de San Adrián (AMSA, en adelante), Cuadernos de labores de la administración de Monteagudo, Cajas 14, 15, 29, 38, 43, 44, 62 y 64. Archivo de los Duques de Miranda (ADM, en adelante), Fajos de cuentas anuales, 1862-1867, 1868-1873, 1874-1881, 1884-1887, 1891-1893 y 1900-1906; y Libros diarios contables, 1911-1918, 1918-1920, 1923-1927 y 1928-1938.

en tareas concretas, como la siega o la trilla, en las que coincidía la urgencia con que debían ejecutarse y el solsticio de verano ${ }^{10}$.

Tan sólo queda reducir a su expresión en dinero el valor de los complementos no monetarios que recibían los jornaleros — que en el sur de Navarra se limitaban casi en exclusiva al jarro de vino-, para poder ofrecer en el Gráfico 2 sendas curvas de los jornales nominales de hombres y mujeres adultos en tareas poco especializadas (binar o edrar, escardar, sembrar alubias, esfornecinar o despampanar, vendimiar, coger olivas, limpiar acequias, arreglar caminos o fincas, limpiar graneros y dependencias, etc.).

10 Referencias a la duración de la jornada en Jaén (1904), pp. 148-205, y García de los Salmones (1915), p. 245, así como en algunas ordenanzas de campo de las que me hago eco en Lana (2002), p. 226. 
Es indudable que construir esta remuneración-tipo es muy útil y no presenta excesivas complicaciones. La figura social que presupone, la del asalariado eventual (el casual labourer de la literatura especializada inglesa), se ajusta perfectamente al marco del capitalismo agrario que se pretende estudiar, al quedar convertida la fuerza de trabajo en una mercancía divisible y negociable entre oferentes y demandantes en un mercado aparentemente abierto y competitivo ${ }^{11}$.

Ahora bien, esta remuneración nos dice más bien poco de los ingresos del trabajador. Es un dato con el que éste debe jugar para diseñar sus estrategias de reproducción, que habitualmente contemplan otras fuentes de ingresos alternativas, a cargo del cabeza de familia o de los demás miembros de la misma. Pero ese dato no constituye en sí mismo más que una parte de lo que determina el ingreso salarial. Desde la perspectiva del trabajador, tan importante como la cuantía de la remuneración diaria es la regularidad de la misma y su distribución en el transcurso del año agrícola. Si de lo que se trata es de determinar el ingreso salarial, las variables que en él intervienen podrían describirse del modo siguiente:

$$
I w=\sum_{i=1}^{n}(w \cdot f \cdot g \cdot h)+\sum_{j=1}^{m}(s \cdot q)+p
$$

Donde Iw designa el ingreso salarial, el sumatorio que encabeza el segundo término de la ecuación representa la suma de los jornales (entendidos como salarios por tiempo) obtenidos durante el año por el cabeza de familia o los demás miembros del grupo doméstico, el segundo sumatorio representa el número de salarios obtenido por piezas o destajos (donde $s$ es el precio del trabajo por unidad de referencia, producto o superficie, y $q$ es la cantidad de producto o superficie trabajados), y finalmente $p$ hace alusión a las gratificaciones, premios, adehalas, gajes $\mathrm{u}$ otro tipo de complementos salariales que quedan a la discrecionalidad del patrón o cuyo valor monetario es difícilmente determinable.

En esta formulación teórica del ingreso salarial merecen destacarse tres ideas. En primer lugar, la importancia de conocer el valor de $n$ y $m$; es decir, el número de días que una familia de asalariados podía esperar contratarse por tiempo o por piezas con uno o varios patronos. Es en ese dato en el que descansaba, más que en el precio del jornal propiamente dicho, la diferencia entre pasar hambre y sobrevivir dignamente, o incluso ahorrar. Es, además, en este ámbito en el que las diferencias entre unas familias de asalariados y otras podían llegar a ser más intensas. Solía suceder que en los contextos en que se recurría a la fuerza de trabajo femenina e infantil, la contra- 
tación del cabeza de familia podía ir acompañada de la de otros miembros del grupo, si lograban ganar la confianza del capataz encargado de la contratación. De este modo, podrían darse casos de familias que lograban introducir de manera regular varios jornales en casa, mientras que otras apenas si podían garantizar unos pocos para uno sólo de sus miembros (generalmente, el padre). Y es que la facultad de contratar un jornal podía ser adecuadamente utilizada para tejer redes de dependencia y clientelismo, con mayor motivo a partir del momento en que se instaura en España el sufragio universal.

En segundo lugar, conviene no perder de vista la relativamente amplia extensión del trabajo a destajo, especialmente en tareas que requerían grandes volúmenes de esfuerzo como eran la siega de cereales, el hoyado y plantación de viñedo, la cava, la recolección de la oliva o la medición de granos. El recurso al destajo cobraba también sentido en coyunturas en que las reclamaciones salariales de los trabajadores locales chocaban con las expectativas del patrón. También en las cuadrillas de destajeros no resultaba raro encontrar varios miembros de una misma familia ${ }^{12}$.

En tercer lugar, resalta la importancia de algunos complementos salariales de difícil determinación, como las gratificaciones o premios ofrecidos por el patrón tras un trabajo juzgado satisfactoriamente, la posibilidad de criar un pequeño hatillo de ganado junto con el del patrón en el caso de los pastores, o la participación en las multas cobradas a los infractores de la ley en el caso de los guardas. También aquí podrían añadirse los seguros y subsidios que se incorporan en los contratos en la década de 1930.

Ahora bien, cumplimentar los términos de la ecuación anterior para construir una serie de ingreso salarial parece una empresa imposible. No existen fuentes que permitan identificar nominalmente a los participantes en el mercado de trabajo y reconstruir sus trayectorias de contratación. La única posibilidad de acercarnos al ingreso salarial es estudiar el caso de los asalariados fijos, en cuya remuneración van embebidas tanto la variable precio como la variable tiempo ${ }^{13}$.

Sin embargo, el análisis del universo de los asalariados fijos presenta también sus propios problemas. De entrada, se trata de una figura aparentemente en declive,

12 Un esquema teórico del sistema salarial como sistema de control de la fuerza de trabajo, en que cobra especial relieve la distinción entre salarios por tiempo (time wage system) y salarios por piezas (incentive wage system), en Gooren y Heger (2003). Florencio y López (2003) analizan el papel de los destajos en el mercado de trabajo andaluz del Antiguo Régimen.

13 Los datos que permiten distinguir entre asalariados fijos y eventuales no están exentos de problemas. Así, para la Merindad de Tudela el Censo de Floridablanca contabilizaba 3.393 jornaleros y 933 criados en 1786, pero diez años más tarde, el Censo de Godoy anotaba 3.634 jornaleros, 88 criados y 397 pastores. Semejante cambio tan sólo puede atribuirse a los mudables criterios que manejaron los autores de los recuentos, aunque sirve para situar la proporción del contrato fijo de trabajo entre el 11,8 y el 21,6 por 100 de los asalariados. Para los datos, AGN, Reino, Estadística, leg.20. 
que presenta problemas de representatividad y de arcaísmo. Así lo ha puesto de relieve la polémica mantenida en el Reino Unido sobre la dicotomía entre servant y labourer en la era de la industrialización, en la que se han destacado su encaje en lógicas de reproducción familiar, el peso de las remuneraciones no monetarias y la naturaleza legal y consuetudinaria de la relación entre empleado y patrono, más cercana al "familismo" que al mercado, para defender su carácter transicional y premoderno ${ }^{14}$.

El proceso de precarización de la fuerza de trabajo agrícola es algo también perceptible en Navarra durante el siglo XIX. Aparte de cambios en las propias administraciones (la hacienda del conde de Zaldívar en Cortes pasó de registrar 10 personas en plantilla gozando de sueldo anual en la década de 1860 a tan sólo dos en 19001903), el declive más intenso pudo producirse como consecuencia de la desamortización eclesiástica. Si entre 1783 y 1807, el monasterio de Fitero mantuvo un promedio de 25 criados cada año y el de La Oliva llegaba a 40 criados entre 1823 y 1834, los marqueses de San Adrián tan sólo mantenían tres criados en su hacienda de Tudela en 1805-1808 y cuatro en la de Monteagudo en 1825-30. Una simple comparación entre la plantilla del monasterio de La Oliva entre 1814 y 1834 (con el paréntesis de 1820-1823, en que se produjo la exclaustración) y la del conde de Zaldívar entre 1862 y 1887 (véase el Cuadro 3) permite comprobar la radical diferencia en cuanto a las pautas de contratación. Mientras que en diecisiete años pasaron por el monasterio 302 criados, en veinticinco el conde de Zaldívar, con una hacienda de casi 900 hectáreas de las que 118 se cultivaban directamente, tan sólo contrató a 66 personas de modo permanente ${ }^{15}$.

Ahora bien, esta preferencia de la hacienda monástica por el asalariado permanente no ha de confundirse con estabilidad en el empleo desde el punto de vista del trabajador. De hecho, una nota característica de ese patrimonio es la intensa rotación de la fuerza de trabajo permanente. Muchos de estos contratos se realizaban por meses, en especial algunos relacionados con el pastoreo ("paricioneros", zagales) y con la labranza ("meseros del campo"); otros establecían una referencia anual, aunque no

14 Moses (1999). Uno de los puntos en discusión ha sido la condición del criado de labranza, que algunos autores han interpretado como ajena al proletariado (Kussmaul, 1981) e incluso como un avatar campesino (Howkins, 1994), mientras que otros han defendido su condición obrera (Anthony, 1995; Caunce, 1997). Otro aspecto del debate ha girado en torno a la desaparición de la figura del servant durante el siglo XIX: mientras que algunos han asociado el declive del farm service con la difusión del capitalismo agrario y con la transformación de la estructura de clases en el mundo rural (Kussmaul, 1981; Hobsbawm y Rudé, 1985), otros autores han desmentido el carácter general de ese proceso, limitándolo al sur y este de Inglaterra, bien sea para defender la persistencia del campesinado en las islas británicas (Howkins, 1994), bien para afirmar un proceso de proletarización complejo, no únicamente asociado a "casualisation", que revelaría la flexibilidad del capitalismo a la hora de desarrollarse dentro de estructuras tradicionales sin destruirlas (Caunce, 1997).

15 Otra nota distintiva es la diversidad de la plantilla del monasterio, donde podemos contar hasta 22 oficios, frente a la simplicidad de la del conde, en la que sólo hallamos cinco figuras. 


\section{CUADRO 3}

TIEMPO DE PERMANENCIA COMO ASALARIADOS FIJOS (POR AÑO O POR MESES), MONASTERIO DE LA OLIVA, 1814-1834, Y HACIENDA DEL CONDE DE ZALDÍVAR EN CORTES, 1862-1887

\begin{tabular}{lccccccccccc}
\hline Años & $\mathbf{1}$ & $\mathbf{2}$ & $\mathbf{3}$ & $\mathbf{4}$ & $\mathbf{5}$ & $\mathbf{6}$ & $\mathbf{7}$ & $\mathbf{8}$ & $\mathbf{9}$ & $\mathbf{1 0 >}$ & Total \\
\hline Número & 144 & 79 & 26 & 19 & 14 & 5 & 6 & 3 & 2 & 4 & 302 \\
Porcentaje & 47,7 & 26,2 & 8,6 & 6,3 & 4,6 & 1,7 & 2,0 & 1,0 & 0,7 & 1,3 & 100,0 \\
\hline \multicolumn{7}{c}{ Conde de Zaldívar (Cortes), 1862-1887 } \\
\hline Número & 19 & 20 & 8 & 9 & 3 & 2 & 1 & 0 & 0 & 4 & 66 \\
Porcentaje & 28,8 & 30,3 & 12,1 & 13,6 & 4,5 & 3,0 & 1,5 & 0,0 & 0,0 & 6,1 & 100,0 \\
\hline
\end{tabular}

Fuentes: AGN, Clero, La Oliva, libro 533; ADM, Fajos de cuentas anuales.

siempre completaban el tiempo estipulado. Así, casi la mitad de los que fueron contratados por el monasterio en esos años apenas llegaron a los doce meses en su puesto. Por el contrario, se percibe una mayor estabilidad entre los escasos empleados del conde de Zaldívar, con tan sólo un 29 por 100 de personas que no llegaron a cumplir un año en el puesto, siendo en su mayor parte muchachos ayudantes de pastor.

Más allá de estas aclaraciones, la elaboración de un indicador sintético de las remuneraciones del asalariado fijo presenta otros problemas. El primero de ellos es el de la dispersión de las remuneraciones en función de las categorías o empleos de los asalariados. No era lo mismo trabajar de "hacedor", equivalente a capataz o mayordomo de campo, que de "criado de azada". No cargaba la misma responsabilidad un mayoral de ganado que un asistente en la época de la parición o que un zagal. No suponían el mismo esfuerzo y responsabilidad trabajar como mulero que como guarda de campos. Y, por supuesto, ninguna de estas figuras podía ser equiparada a la del administrador general. Para cada una de estas funciones el reclutamiento de personal solía seleccionar a los candidatos atendiendo a su extracción social: así, para las funciones con responsabilidad en la organización del trabajo (hacedores, sobrestantes, mayordomos, mayorales) los empleados solían proceder de familias de "labradores"; el resto de ocupaciones que no conllevaban especiales conocimientos o responsabilidad (guardas, muleros, criados de campo, etc) solían reclutarse entre familias de "jornaleros"; y, en el otro lado, los administradores solían ser habitualmente ellos mismos "hacendados". 
El Cuadro 4 sintetiza algunas de las remuneraciones monetarias percibidas por distintas categorías de asalariados fijos en varias explotaciones del sur de Navarra, tanto laicas como eclesiásticas. La nota distintiva es la dispersión, pero no únicamente entre diferentes categorías, sino que incluso dentro de la misma figura podemos hallar remuneraciones monetarias muy diferentes según la hacienda de que se trate. Así, mientras que los guardas del monasterio de Fitero percibían, en 1815-1834, el equivalente a 7,84 pesetas al mes, los de La Oliva ganaban 8,12, quedando ambas cuantías a gran distancia de las 22,81 pesetas que pagaba el marqués de San Adrián a su guarda de campos. Incluso dentro de la misma categoría laboral y en la misma administración se perciben cambios de nivel que no podemos calificar sino de insólitos.

Podría buscarse una explicación a este fenómeno planteando la hipótesis de que, a diferencia de los mercados de trabajo eventual, abiertos y fluidos, los mercados que regían la contratación de asalariados fijos pudieran ser mercados segmentados, poco permeables y escasamente transparentes, lo cual dificultaría la movilidad e impediría la formación de un precio único, incluso a nivel regional y local. Ello cuadraría bien con la caracterización de la figura del servant como premoderna y más cercana al campesinado que al proletariado. Sin embargo, una parte importante de esta dispersión salarial puede ser explicada de una forma más sencilla, dando entrada a la valoración de los complementos no monetarios del salario ${ }^{16}$.

Los libros de cuentas de los monasterios de Fitero y La Oliva recogen regularmente el consumo de productos por parte del personal contratado. Así, en Fitero se detalla, entre 1783 y 1792, el trigo consumido por los pastores y criados, lo cual ha permitido calcular un gaje de 0,52 hectolitros de trigo y 0,13 de cebada por mes ${ }^{17}$. Por su parte, la presencia de un "gasto en portería y familia" de 254,13 hectolitros de trigo anuales en La Oliva, ha servido para estimar un gaje de 0,52 al mes por asalariado fijo. A diferencia del monasterio de Fitero, enclavado en un casco urbano con 2.241 habitantes en 1786, el de La Oliva se halla en despoblado, por lo que he considerado que se daba alojamiento a los criados en las dependencias del monasterio, de modo que la valoración de los complementos de estos asalariados incluye tanto el trigo como la vivienda.

En el caso de los asalariados fijos en administraciones laicas, los complementos no monetarios parecen reducirse a la vivienda. Así ocurre con los guardas contratados por el conde de Zaldívar para custodiar sus cuatro cotos redondos, a quienes se alojaba en los mismos. Así sucedía también en el caso del guarda de las empeltrerías de Monteagudo, a quien desde 1825 hasta 1830 se pagaba a razón de 3 reales de vellón diarios "y casa para vivir"18. También entre 1825 y 1830 se anotaba el salario

\footnotetext{
16 Ballesteros (1999) constata la trascendencia de los complementos no monetarios de las remuneraciones de los trabajadores fijos en la Castilla del siglo XIX.

17 Los 168 hectolitros de trigo se han dividido entre los 27 criados que mantuvo Fitero entre 1783 y 1792 . En el caso del mayoral de ovejas, las cuentas reflejan la entrega de un plus de 4 robos de trigo al año $(0,094$ hectolitros al mes) que se ha añadido al gaje común.
} 


\section{CUADRO 4}

SUELDOS EN METÁLICO POR CATEGORÍAS DE ASALARIADOS FIJOS, SUR DE NAVARRA, 1783-1939 (pesetas corrientes por mes)

\begin{tabular}{lccccccccc}
\hline Tipo de criado & Administración & $\mathbf{1 7 8 3 - 0 8}$ & $\mathbf{1 8 1 5 - 3 4}$ & $\mathbf{1 8 3 5 - 6 1}$ & $\mathbf{1 8 6 2 - 8 7}$ & $\mathbf{1 8 8 8 - 1 3}$ & $\mathbf{1 9 1 5 - 3 1}$ & $\mathbf{1 9 3 2 - 3 9}$ \\
\hline Administrador & MSA (Tudela) & 137,50 & 86,59 & 25,67 & 20,43 & - & - & - \\
Administrador & MSA (Monteagudo) & 55,65 & 68,69 & 68,49 & 69,34 & 91,27 & - & - \\
Administrador & $\mathrm{CdZ}$ & - & - & - & 250,00 & 125,00 & 312,96 & 416,66 \\
\hline Sobrestante & $\mathrm{MSA}$ & - & 34,55 & 30,53 & 30,43 & 39,72 & - & - \\
Hacedor & $\mathrm{MO}$ & - & 10,57 & - & - & - & - & - \\
Guarda mayor & $\mathrm{CdZ}$ & - & - & - & 57,51 & 75,00 & 108,00 & 148,75 \\
Guarda & $\mathrm{MSA}$ & - & 22,81 & - & - & - & & \\
Guarda & $\mathrm{CdZ}$ & - & - & - & 55,25 & 52,53 & 72,83 & 146,52 \\
Guarda & $\mathrm{MF}$ & 5,66 & 7,84 & - & - & - & - & - \\
Guarda & $\mathrm{MO}$ & - & 8,12 & - & - & - & - & - \\
Guarda & $\mathrm{Ay} . \mathrm{Vf}$. & - & - & 14,13 & 35,33 & 42,56 & - & - \\
\hline Mulero & $\mathrm{MSA}$ & 41,13 & 30,92 & 33,07 & 31,20 & 33,15 & - & - \\
Mulero/boyero & $\mathrm{MF}$ & 9,45 & 8,64 & - & - & - & - & - \\
Mulero & $\mathrm{MO}$ & - & 9,90 & - & - & - & - & - \\
Mayoral & $\mathrm{MF}$ & 10,35 & 10,29 & - & - & - & - & - \\
Mayoral & $\mathrm{MO}$ & - & 10,14 & - & - & - & - & - \\
Mayoral & $\mathrm{CdZ}$ & - & - & - & 32,29 & - & - & - \\
\hline Zagal & $\mathrm{MF}$ & 5,61 & - & - & - & - & - & - \\
Zagal & $\mathrm{CdZ}$ & - & - & - & 19,24 & - & - & - \\
\hline
\end{tabular}

Abreviaturas: MSA, marqués de San Adrián (Tudela y Monteagudo); CdZ, conde de Zaldívar (Cortes); MF, monasterio de Fitero; MO, monasterio de La Oliva; Ay.Vf., Ayuntamiento de Villafranca.

Fuentes: Las mismas del Gráfico 2 y AMSA, Cuentas Generales, cajas 11, 14, 15, 17-19, 24, 25, 30, 33, 34, 38, 41, 43, $49,50,53,55,58$ y 62 .

del sobrestante "a respecto de 5 reales diarios que le señaló S(u) E(xcelencia) en esta villa y casa para vivir", rebajándolo desde 1831 a 4 reales y la vivienda. No ocurría lo mismo en el caso de los dos muleros o "criados de labranza", a quienes entre 1802 y 1808 se pagaba a razón de 6 reales los 293 días de trabajo y a 3 los 72 días de fiesta. Desde 1825 se redujo esa paga a 5 y 2 reales, respectivamente, "con obligación de dormir en la cuadra para el mejor cuidado de las caballerías". Al año siguiente vol-

18 AMSA, caja 33. En 1831 se despidió al guarda "por haberse arrendado el guardío de campos en general conforme a la ley", AMSA, caja 25. 


\section{CUADRO 5}

ESTIMACIÓN DE LA REMUNERACIÓN GLOBAL, EN METÁLICO Y EN ESPECIE, POR CATEGORÍAS DE ASALARIADOS FIJOS, SUR DE NAVARRA, 1783-1939

(pesetas corrientes por mes)

\begin{tabular}{|c|c|c|c|c|c|c|c|c|}
\hline Tipo de criado & Administración & 1783-08 & $1815-34$ & $1835-61$ & $1862-87$ & $1888-13$ & $1915-31$ & $1932-39$ \\
\hline Sobrestante & MSA & - & 41,41 & 37,38 & 38,63 & 47,61 & - & - \\
\hline Hacedor & MO & - & 23,44 & - & - & - & - & - \\
\hline Guarda mayor & $\mathrm{CdZ}$ & - & - & - & 65,71 & 84,39 & 121,80 & 173,70 \\
\hline Guarda & MSA & - & 27,73 & - & - & - & - & - \\
\hline Guarda & $\mathrm{CdZ}$ & - & - & - & 60,42 & 58,92 & 82,94 & 168,44 \\
\hline Guarda & MF & 17,82 & 21,17 & - & - & - & - & - \\
\hline Guarda & MO & - & 21,00 & - & - & - & - & - \\
\hline Mulero & MSA & 41,13 & 30,92 & 33,07 & 31,20 & 33,15 & - & - \\
\hline Mulero & MF & 21,62 & 21,96 & - & - & - & - & - \\
\hline Mulero & MO & - & 22,18 & - & - & - & - & - \\
\hline Mayoral & MF & 24,27 & 25,54 & - & - & - & - & - \\
\hline Mayoral & MO & - & 22,29 & - & - & - & - & - \\
\hline Mayoral & $\mathrm{CdZ}$ & - & - & - & 32,29 & - & - & - \\
\hline
\end{tabular}

Fuentes: Las mismas del Cuadro 4.

vió a alterarse ese sueldo, entregando 4 reales cada uno de los 365 días del año, sin referencia alguna a otro tipo de complementos salariales ${ }^{19}$.

Con estas advertencias podemos retomar el análisis de las series de las remuneraciones de criados con mayores garantías. El Cuadro 5 sintetiza esta información, en la cual se ha reducido de modo muy notable la dispersión que antes hallábamos. Aún así, continúa existiendo un importante desnivel en cuanto a las remuneraciones percibidas incluso dentro de la misma categoría laboral en distintas localidades y administraciones. Particularmente llamativa resulta la diferencia de salario entre los

19 El complemento salarial en vivienda se ha valorado de modo diferente dependiendo del tipo de contrato. El sueldo de los criados de labranza y guardas se ha completado con la serie de alquileres de viviendas ordinarias (menos de 100 pesetas); el de los criados de confianza (sobrestante, mayordomo, capataz, hacedor) incorpora la serie de alquiler medio global. 


\section{GRÁFICO 3}

ÍNDICE DE LA REMUNERACIÓN TOTAL DEL ASALARIADO FIJO, SUR DE NAVARRA, 1783-1936 (base $100=1783$ )

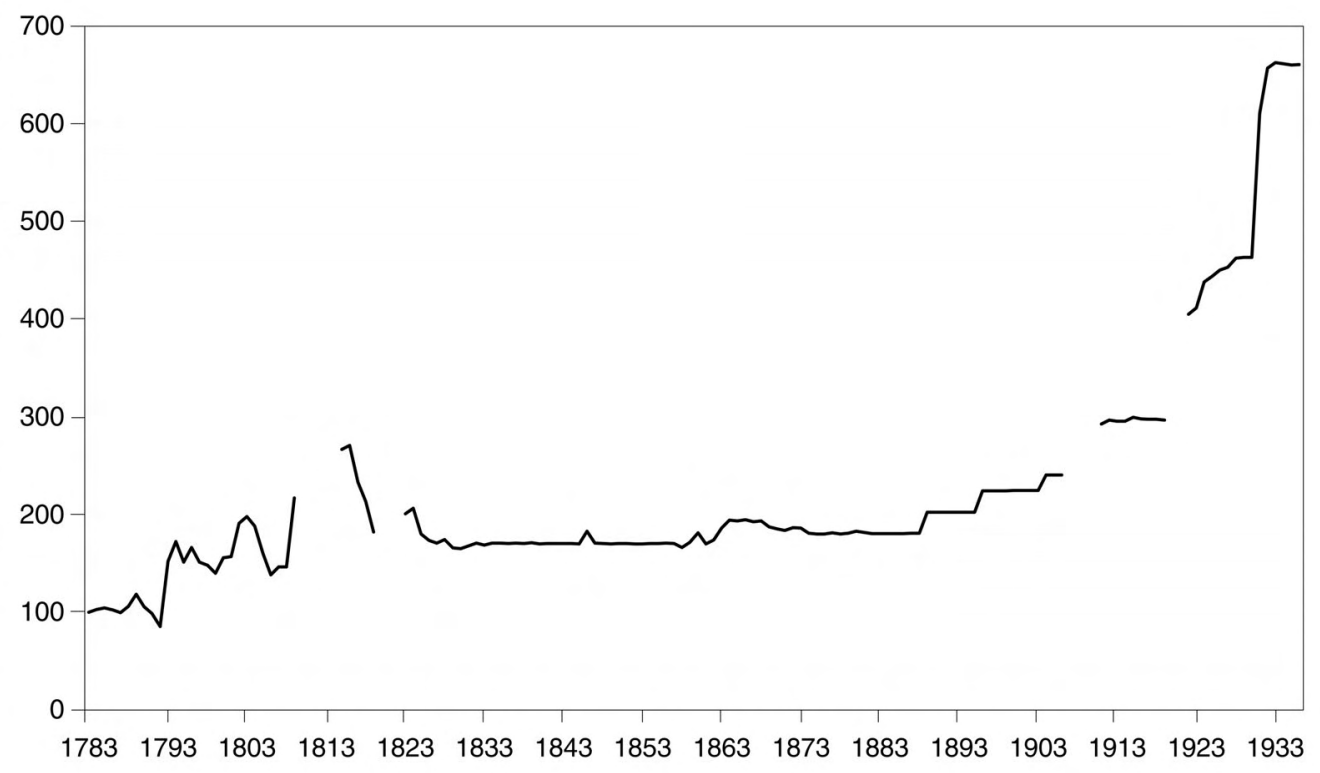

Fuentes: Las mismas del Cuadro 4.

sobrestantes de la familia Magallón en Monteagudo y Tudela y la de los guardas de cotos de Hurtado de Zaldívar en Cortes. De cualquier forma, los primeros, del mismo modo que los mayorales, contaban con un plus intangible derivado de su papel en la organización del trabajo y en la contratación, que no era otro que el de poder incorporar a los contratos a familiares y amigos, y el de ejercer un papel de intermediarios entre el propietario y la comunidad local.

¿Es sensato estimar a partir de estas series algún indicador sintético de la evolución de los salarios de los criados? Una respuesta positiva no parece descabellada, ya que lo que nos interesa no es tanto la evolución de la cuantía del sueldo como la tendencia de éste. Por ello, se han reducido las series de salarios (incluidos los complementos no monetarios) a series de incrementos anuales en porcentajes. Promediados año a año tales incrementos, se ha construido un índice de la remuneración del asalariado fijo a partir de los casos de capataces, guardas, muleros y mayorales. Tan sólo cabe añadir que los huecos en la información (1809-1813, 1820-1822, 1907-1910 y 19201921) se han resuelto calculando el porcentaje de aumento del primer año tras el paréntesis sobre el último año antes del mismo. El índice obtenido (véase el Gráfico 3) reco- 


\section{CUADRO 6}

EVOLUCIÓN DEL COSTE DE LA VIDA, LOS SALARIOS AGRÍCOLAS Y SU CAPACIDAD ADQUISITIVA EN NAVARRA, 1781-1936

\begin{tabular}{|c|c|c|c|c|c|c|c|c|c|c|}
\hline & $1781-99$ & $1800-15$ & $1816-30$ & $1831-45$ & $1846-60$ & $1861-75$ & $1876-90$ & $1891-05$ & $1906-20$ & $1921-36$ \\
\hline \multicolumn{11}{|c|}{ Coste de la vida } \\
\hline Índice I & 85,2 & 115,9 & 83,0 & 76,7 & 81,6 & 94,8 & 105,0 & 104,7 & - & - \\
\hline Índice II & - & - & - & - & - & 92,6 & 104,4 & - & 122,4 & 191,3 \\
\hline \multicolumn{11}{|c|}{ Salarios nominales } \\
\hline Jornal hombre & 62,4 & 77,8 & 73,0 & 66,6 & 74,9 & 93,0 & 108,6 & 100,0 & 138,5 & 290,3 \\
\hline Jornal mujer & 43,1 & 69,7 & 61,7 & 60,0 & 74,5 & 93,2 & 104,1 & 103,3 & 140,2 & 290,4 \\
\hline Salario criados & 58,0 & 83,7 & 91,3 & 79,8 & 80,5 & 87,2 & 86,1 & 102,7 & 136,4 & 246,6 \\
\hline \multicolumn{11}{|c|}{ Capacidad adquisitiva } \\
\hline Jornalero & 75,0 & 68,2 & 90,0 & 88,5 & 92,6 & 98,4 & 103,6 & 96,2 & 116,8 & 152,5 \\
\hline Bracera & 55,6 & 62,0 & 76,7 & 79,4 & 91,7 & 98,8 & 99,7 & 100,4 & 119,2 & 153,0 \\
\hline Criado & 66,8 & 78,4 & 109,6 & 106,7 & 101,3 & 92,5 & 82,4 & 98,5 & 122,4 & 128,7 \\
\hline
\end{tabular}

Fuentes: Apéndice 1 y Ballesteros (1997).

ge un notable escalón a partir de 1793, debido más al aumento de valor del trigo recibido como salario que al de la parte monetaria del mismo. Tras el reajuste a la baja después de la guerra napoleónica, la serie muestra una prolongada estabilidad con algunos escalones menores en 1863, 1889 y 1896, antes de que se desencadenase una nueva escalada en la segunda y tercera décadas del siglo XX.

\section{La capacidad adquisitiva de los asalariados}

El recorrido efectuado hasta el momento nos pone en situación de poder abordar el análisis de la evolución de la capacidad adquisitiva de los salarios agrícolas en Navarra entre las décadas de 1780 y 1930. Los resultados del ejercicio se sintetizan en el Cuadro 6 y en el Gráfico 4. 


\section{GRÁFICO 4}

ÍNDICES DE LA CAPACIDAD ADQUISITIVA DE LOS SALARIOS AGRÍCOLAS EN NAVARRA

(medias móviles de 3 años, base $100=1891-1900$ )

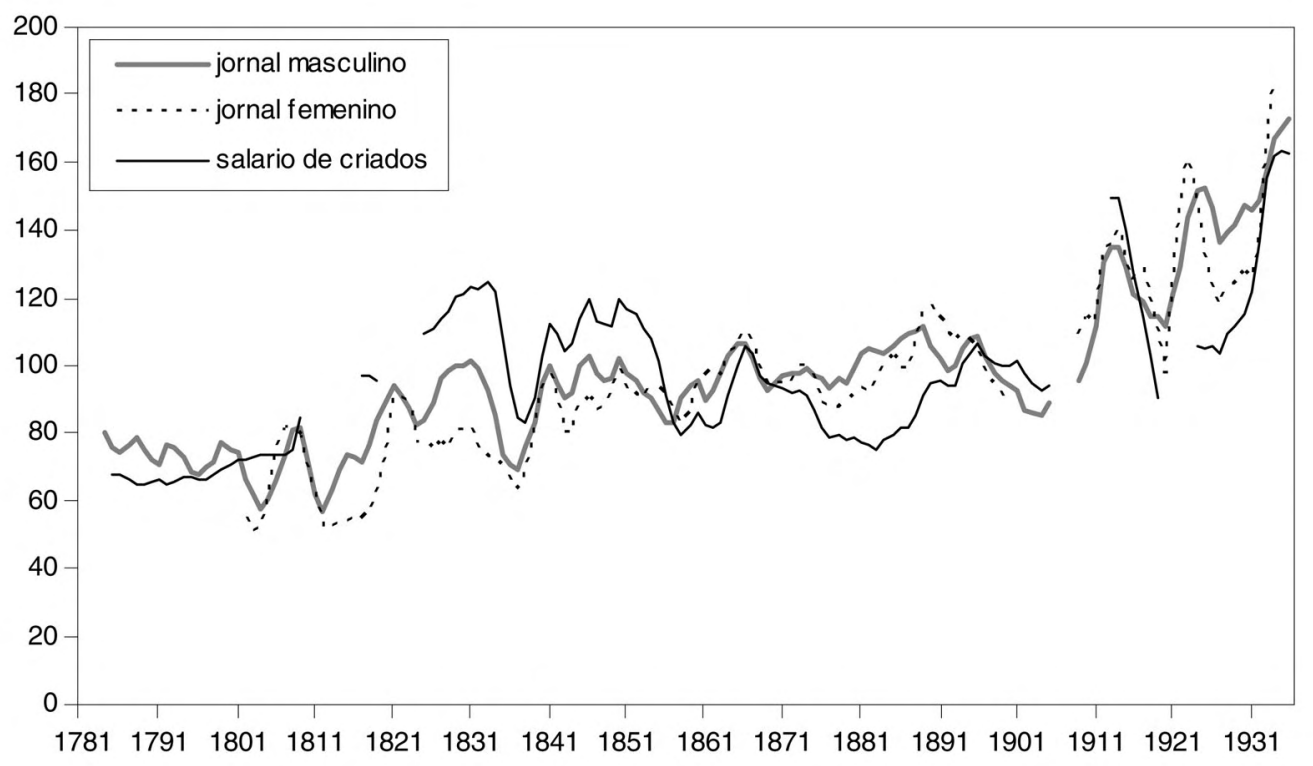

Fuentes: Las mismas del Cuadro 6.

La primera idea que cabe destacar es que las categorías de trabajadores analizadas experimentaron evoluciones muy diversas en el detalle, aunque coincidentes en su tendencia general. A largo plazo, los mayores avances en la capacidad adquisitiva de su remuneración correspondieron a las mujeres contratadas eventualmente, ya que partían de una base más baja y alcanzaron en el lapso 1921-1936 un índice homologable al del trabajador varón. Indagar en esta dirección para determinar causas y consecuencias de naturaleza económica o social es algo que escapa a los objetivos de este artículo, pero quede al menos constancia del hecho ${ }^{20}$. Por lo que hace a los trabajadores varones, también desde una perspectiva de muy largo plazo, se aprecia un mayor avance en la capacidad adquisitiva de los trabajadores eventuales que de los asalariados fijos, ya que los primeros multiplicaron por dos su índice medio entre 1781-1799 y 1920-1936, y los segundos se situaron diez décimas más abajo.

20 Borderías y Sarasúa (2005) abordan expresamente el análisis de las remuneraciones de las trabajadoras rurales y urbanas en Cataluña. 
Pero más que estas diferencias, no demasiado abultadas en el balance a largo plazo, llama la atención la dispar evolución durante las diferentes coyunturas que jalonan este siglo y medio. La mayor rigidez de la remuneración de los criados jugó a su favor durante el período posterior a las guerras napoleónicas, cuando las caídas de precios de los productos agrarios generaron un crecimiento "pasivo" de su capacidad adquisitiva. Se trata, no obstante, de un lapso en el que probablemente se está asistiendo a una profunda remodelación de los mercados de trabajo agrario, precisamente en detrimento de este tipo de contratos, tal como se ha argumentado en páginas anteriores. Por el contrario, en la etapa posterior, caracterizada por una sostenida alza de precios, la estabilidad del salario de los criados determinó un progresivo deterioro de su capacidad adquisitiva que no sería corregido hasta el cambio de siglo.

Por su parte, la capacidad adquisitiva de los jornaleros presenta un aumento más moderado en el primer tercio del Ochocientos. Una parte de ese avance no es sino la recuperación del deterioro experimentado durante las dos últimas décadas del siglo XVIII. Pero, pese a todo, hay un incremento del poder de compra que, tras un desfallecimiento durante la primera guerra carlista, se verá confirmado en el resto de la centuria. Durante el primer tercio del siglo XX, el comportamiento de la capacidad adquisitiva del jornalero presenta igualmente un mayor empuje que el del criado, que, de nuevo, se revela más rígido ante las fluctuaciones de los mercados.

La divergencia entre las respectivas evoluciones de la capacidad de compra de jornalero y criado alcanza un grado máximo en dos coyunturas alejadas en el tiempo. Entre 1789 y 1805, al tiempo que el jornalero veía deteriorarse su poder de compra, el criado experimentaba la tendencia contraria, gracias al peso que en su remuneración tenían los complementos en especie, particularmente el trigo, en un contexto inflacionario. Lo contrario ocurre entre 1870 y 1885, cuando coincide una pérdida de capacidad de compra del criado con una mejora de la del jornalero. Claro que, entre ambas fechas, median profundos cambios tanto en los mercados de trabajo (como la eliminación legal en 1817 del sistema de determinación administrativa de los jornales o el arrinconamiento paulatino del contrato estable) como en las estructuras de propiedad de la tierra y los mercados agrarios. En ese nuevo contexto, el salario del jornalero respondió mejor a las tensiones generadas por el boom vitivinícola de 1880 — al igual que lo había hecho en la década de 1850—, permitiéndole mejorar su posición negociadora, cosa que no pudo hacer en la misma medida el trabajador fijo, sometido a unas condiciones de contratación más rígidas. 


\section{Conclusiones}

En suma, las curvas presentadas confirman, con matices, algunas ideas planteadas en artículos previos acerca de la evolución de la capacidad adquisitiva de los asalariados agrícolas: la existencia de dos momentos que registran un potente aumento del poder de compra, el primero de ellos entre 1815 y 1830 y el segundo entre 1910 y 1936, en medio de fuertes fluctuaciones en el corto plazo, la recurrencia de coyunturas especialmente adversas, y una prolongada estabilidad durante los dos últimos tercios del siglo XIX. Los nuevos datos incorporados a las series permiten afirmar que el crecimiento del poder de compra posterior a 1815 fue algo más que una mera recuperación de la capacidad adquisitiva perdida durante el ciclo inflacionario anterior. Particularmente beneficiosa resultó para quienes podían acceder a contratos estables, que multiplicaron por 1,6 su poder de compra frente al escaso 1,2 de los jornaleros.

Pero, en definitiva, ¿le fue bien o le fue mal al trabajador agrícola navarro durante el período de definitiva penetración del capitalismo en el campo? ¿Le fue mejor o peor que al de otros lugares? En el Cuadro 7 se aportan algunos elementos para responder a estas cuestiones. Por un lado, se han reelaborado las series de Clark para la Inglaterra rural, de Geary y Stark para Irlanda y de Moreno para Palencia, a fin de poder establecer comparaciones con las series navarras; también se han ajustado las series de números índices para situar la base 100 en el decenio 1791-1800. Por otro, se ha ensayado la reducción de las dos series del jornalero y del criado del sur de Navarra a una única serie del asalariado agrícola. Para ello se han tenido en cuenta las proporciones que representaban jornaleros y criados en el censo de $1860^{21}$.

El comportamiento de los asalariados navarros, tan distintos entre sí, presenta rasgos originales, aunque no faltan puntos de conexión con las otras series manejadas. En todos los casos, la deflación postnapoleónica jugó a favor del poder de compra de los trabajadores, aunque en grados diferentes. Llama la atención la escasa sintonía entre la capacidad de compra del jornalero navarro y la de su homólogo palentino entre 1790 y 1830, habida cuenta de la escasa distancia entre las cuencas del Ebro y del Duero. La línea trazada por éste último, sin embargo, presenta una gran similitud con la del criado navarro, lo cual apunta a que en ambos casos la rigidez del salario pudo jugar a su favor en un contexto de deflación ${ }^{22}$. No obstante, a partir de

21 Las ponderaciones que se han empleado para elaborar el índice de salarios reales agrícolas son fijas y toman como referencia el número de jornaleros de campo, sirvientes masculinos y sirvientes femeninos que el censo de 1860 atribuye al partido judicial de Tudela. La fuerza de trabajo agrícola se compondría, así, de un 68,2 por 100 de jornaleros, un 16,1 de criados y un 15,7 de trabajadoras.

22 La serie palentina parece homologable, en efecto, a la serie navarra del criado, ya que se trata de "braceros no temporeros", y advierte el autor que no incluye en los cálculos ciertas figuras de asalariados "debido al vínculo laboral mucho más esporádico y discontinuo que mantenían con el hospital" (Moreno, 2002, p. 89). 


\section{CUADRO 7}

ÍNDICES DE LOS SALARIOS REALES AGRÍCOLAS EN NAVARRA, PALENCIA, INGLATERRA E IRLANDA, 1781-1900 $($ base $100=1791-1800)$

\begin{tabular}{lcccccc}
\hline & Inglaterra & Irlanda & Palencia & \multicolumn{3}{c}{ Navarra } \\
\cline { 5 - 7 } & & & & Jornalero & Criado & $\begin{array}{c}\text { Salario } \\
\text { medio }\end{array}$ \\
\hline $\mathbf{1 7 8 1 - 1 7 9 0}$ & 104 & 107 & 110 & 104 & 98 & 103 \\
$\mathbf{1 7 9 1 - 1 8 0 0}$ & 100 & 100 & 100 & 100 & 100 & 100 \\
$\mathbf{1 8 0 1 - 1 8 1 0}$ & 98 & 98 & 118 & 93 & 114 & 96 \\
$\mathbf{1 8 1 1 - 1 8 2 0}$ & 105 & 95 & 135 & 103 & 144 & 103 \\
$\mathbf{1 8 2 1 - 1 8 3 0}$ & 124 & 128 & 162 & 128 & 170 & 131 \\
$\mathbf{1 8 3 1 - 1 8 4 0}$ & 130 & 131 & 101 & 116 & 155 & 121 \\
$\mathbf{1 8 4 1 - 1 8 5 0}$ & 144 & 126 & 106 & 133 & 166 & 137 \\
$\mathbf{1 8 5 1 - 1 8 6 0}$ & 149 & 147 & 121 & 122 & 139 & 126 \\
$\mathbf{1 8 6 1 - 1 8 7 0}$ & n.d. & 194 & n.d. & 135 & 139 & 137 \\
$\mathbf{1 8 7 1 - 1 8 8 0}$ & n.d. & n.d. & n.d. & 133 & 124 & 131 \\
$\mathbf{1 8 8 1 - 1 8 9 0}$ & n.d. & n.d. & n.d. & 146 & 124 & 143 \\
$\mathbf{1 8 9 1 - 1 9 0 0}$ & n.d. & n.d. & n.d. & 137 & 148 & 140 \\
\hline
\end{tabular}

Fuentes: Para Inglaterra, Clark (2001); para Irlanda, Geary y Stark (2004); para Palencia, Moreno (2002); y para Navarra, las fuentes ya citadas.

1830 el poder de compra del criado navarro y del jornalero palentino divergen abiertamente, debido al derrumbe de la capacidad adquisitiva de este último.

Por lo demás, y salvando las distancias, la evolución del poder de compra del jornalero navarro muestra durante esa etapa una trayectoria a grandes rasgos similar a la de los trabajadores rurales de Inglaterra e Irlanda. Tras una caída entre las décadas de 1780 y 1800 (que se prolonga una década más en el caso irlandés), los jornales reales crecieron en una tercera parte hasta la década de 1830. A partir de ese momento las trayectorias siguieron líneas diferentes. Mientras que en las islas británicas los salarios reales en la agricultura continuaron creciendo (hasta situarse en un índice 150 en la década de 1850 y prácticamente doblarse en el caso de Irlanda durante la década siguiente), la capacidad adquisitiva del jornalero navarro se estancó, e incluso descendió en las décadas de 1850 y 1870. Las transformaciones estructurales de la economía británica y la emigración masiva en el caso irlandés terminaron por jugar también a favor de los asalariados rurales de las islas, al tiempo que el 
capitalismo agrario en Navarra apenas permitía mejorar la suerte del proletariado por el lado de sus ingresos monetarios. En compensación, la posibilidad de roturar terrenos en los baldíos y la apertura de un proceso de parcelación y reparto del comunal (en especial, desde 1907) permitió al jornalero del sur de Navarra consolidar su acceso a la tierra y complementar sus magras rentas con otro tipo de ingresos. Habiéndose asegurado así un bajo nivel para los salarios reales, que eran compensados a través de otras vías, la continuidad del proceso de acumulación y de crecimiento de la renta agraria no se vio comprometida durante el período histórico marcado por el signo de la gran propiedad.

\section{Fuentes}

Archivo General de Navarra

Clero, Fitero, libro 458; La Oliva, libro 533; Tulebras, libro 324; Papeles sueltos, caja 34.084 .

Arteta, cajas 13-15; Baronía de La Torre, cajas 1, 12, 24 y 26; y Reino, Estadística, leg. 20.

Archivo de los Marqueses de San Adrián

Cuentas Generales, cajas 11, 14, 15, 17-19, 24, 25, 30, 33, 34, 38, 41, 43, 49, 50, 53, 55,

58 y 62; Cuadernos de labores de la administración de Monteagudo, cajas 14, 15, 29, $38,43,44,62$ y 64 .

Archivo de los Duques de Miranda (Traibuenas, Navarra)

Fajos de cuentas anuales, 1862-1867, 1868-1873, 1874-1881, 1884-1887, 1891-1893 y

1900-1906; Libros diarios contables, 1911-1918, 1918-1920, 1923-1927 y 1928-1938;

Libro de Frutos, 1859-1889.

Archivo Municipal de Logroño

Fondo Marqués de San Nicolás, Mayorazgo de Sola, caja 12 (30-33).

Archivo Municipal de Cascante

Catastro, Expediente de rentas fijas de los hacendados forasteros de Cascante, 18501874 y $1875-1880$.

Archivo Municipal de Pamplona

Casa de Misericordia, legs. 22-66 y 68-76; Carnicerías, legs. 8-15 y 80-114.

Archivo de la Casa de Misericordia de Pamplona

cajas 43, 59, 81, 82, 86, 270, 271 y 272. 


\section{Bibliografía}

ALLEN, Robert C.; BENGTSSON, Tommy, y DRIBE, Martin (eds.) (2005): Living Standards in the Past. New Perspectives on Well-Being in Asia and Europe, Oxford, Oxford University Press.

ANTHONY, Richard (1995): "Farm Servant vs. Agricultural Labourer, 1870-1914: A Commentary on Howkins", Agricultural History Review, 43, 1, pp. 61-64.

ASTIGARRAGA, Jesús (ed.) (1996): Ilustración y economía en Navarra (1770-1793). El pensamiento económico de José María Magallón y Francisco Javier de Argaiz, VitoriaGasteiz, Servicio Central de Publicaciones del Gobierno Vasco.

BALLESTEROS DONCEL, Esmeralda (1997): “Una estimación del coste de la vida en España, 1861-1936", Revista de Historia Económica, 15, 2, pp. 363-395.

-(1999): "Retribuciones, poder adquisitivo y bienestar material de las clases populares. España y Castilla en la segunda mitad del siglo XX", en TORRAS, Jaume, y YUN, Bartolomé (eds.), Consumo, condiciones de vida y comercialización. Cataluña y Castilla, siglos XVII-XIX, Ávila, Junta de Castilla y León, pp. 229-244.

BARQUÍN, Rafael (2001): “Primera aproximación al coste de la vida en España, 18151860", en SUDRIÀ, Carles, y TIRADO, Daniel (eds.), Peseta y protección. Comercio exterior, moneda y crecimiento económico en la España de la restauración, Barcelona, Universidad de Barcelona, pp. 303-315.

BORDERÍAS, Cristina, y SARASÚA, Carmen (2005): "Salarios de mujeres y hombres en la provincia de Barcelona, segunda mitad del siglo XIX", en VIII Congreso de la Asociación Española de Historia Económica, Santiago de Compostela, 13-16 septiembre.

BURNETTE, Joyce (2004): “The wages and employment of female day-labourers in English agriculture, 1740-1850", Economic History Review, 57, 4, pp. 664-690.

CAUNCE, Stephen (1997): "Farm Servants and the Development of Capitalism in English Agriculture", Agricultural History Review, 45, 1, pp. 49-60.

CLARK, Gregory (2001): "Farm wages and living standards in the industrial revolution: England, 1670-1869", Economic History Review, 54, 3, pp. 477-505.

COLOMÉ, Josep; SAGUER, Enric, y VICEDO, Enric (2002): “Las condiciones de reproducción económica de las unidades familiares campesinas en Cataluña a mediados del siglo XIX", en MARTÍNEZ CARRIÓN, José Miguel (ed.), El nivel de vida en la España rural, siglos XVIII-XX, Alicante, Universidad de Alicante, pp. 321-356.

DEL MORAL RUIZ, Joaquín (1979): La agricultura española a mediados del siglo XIX (1850-1870), Madrid, Ministerio de Agricultura, Pesca y Alimentación.

DUBERT, Isidro (2005): “Criados, estructura económica y social y mercado de trabajo en la Galicia rural a finales del Antiguo Régimen", Historia Agraria, 35, pp. 926. 
ENGERMAN, Stanley L. (1994): "Reflections on 'The Standard of Living Debate': New arguments and new evidence", en JAMES, John A., y THOMAS, Mark (eds.), Capitalism in context. Essays on Economic Development and Cultural Change in Honour of R. M. Hartwell, Chicago, University of Chicago Press, pp. 50-79.

FEINSTEIN, Charles H. (1998): "Pessimism perpetuated: Real Wages and the Standard of Living in Britain during and after the Industrial Revolution", The Journal of Economic History, 58, 3, pp. 625-659.

FERNÁNDEZ ROMERO, Cayetano (2003): “Rentas familiares y niveles de vida en Navarra, siglos XVI-XIX", en FERNÁNDEZ ROMERO, Cayetano, y MORENO, Antonio (eds.), Familia y cambio social en Navarra y País Vasco, siglos XIII al XX, Pamplona, Instituto de Ciencias para la Familia, pp. 275-294.

FLORENCIO PUNTAS, Antonio, y LÓPEZ MARTÍNEZ, Antonio Luis (2000): “El trabajo asalariado en la agricultura de la Baja Andalucía. Siglos XVIII y XIX", Historia Agraria, 21, pp. 99-126.

-(2003): “El mercado de trabajo en la Andalucía latifundista del Antiguo Régimen: ¿Intervencionismo o contratación?", Historia Agraria, 30, pp. 63-86.

GARCÍA DE LOS SALMONES, Nicolás (ed.) (1915): Monografía agrícola de Navarra, impresa por acuerdo de S. E. la Diputación para repartirla a todos los Ayuntamientos de la provincia, Pamplona, Diputación Foral de Navarra.

GARRABOU, Ramón (1987): "Salarios y proletarización en la agricultura catalana de mediados del siglo XIX", Hacienda Pública Española, 108-109, pp. 343-359.

GARRABOU, Ramón, y TELLO, Enric (2002): “Salario como coste, salario como ingreso: el precio de los jornales agrícolas en la Cataluña contemporánea (17271930)", en MARTÍNEZ CARRIÓN, José Miguel (ed.), El nivel de vida en la España rural, siglos XVIII-XX, Alicante, Universidad de Alicante, pp. 183-233.

GARRIDO GONZÁLEZ, Luis (1997): “La configuración de una clase obrera agrícola en la Andalucía contemporánea: los jornaleros", Historia Social, 28, pp. 41-67.

GEARY, Frank, y STARK, Tom (2004): “Trends in real wages during the industrial revolution: a view from across the Irish Sea", Economic History Review, 57, 2, pp. 362-395.

GOOREN, Henny, y HEGER, Hans (2003): “Wage forms, wage systems and labour control in nineteenth-century agriculture. Evidence from the Dutch province of Groningen", en SCHOLLIERS, Peter, y SCHWARZ, Leonard (eds.), Experiencing Wages: Social and cultural aspects of wage forms in Europe since 1500, New York, Berghahn, pp. 139-154.

HOBSBAWN, Eric J., y RUDÉ, George (1985): Revolución industrial y revuelta agraria. El capitán Swing, Madrid, Siglo XXI, pp. 23-100.

HOFFMAN, Philip J.; JACKS, David S.; LEVIN, Patricia A., y LINDERT, Peter H. (2005): "Sketching the Rise of Real Inequality in Early Modern Europe", en ALLEN, Robert C.; BENGTSSON, Tommy, y DRIBE, Martin (eds.), Living Standards 
in the Past. New Perspectives on Well-Being in Asia and Europe, Oxford, Oxford University Press, pp. 131-172.

HOWKINS, Alun (1994): "Peasants, Servants, and Labourers: The Marginal Workforce in British Agriculture, c.1870-1914", Agricultural History Review, 42, 1, pp. 49-62.

JAÉN, Celso (1904): Memoria sobre la tierra labrantía y el trabajo agrícola en la provincia de Navarra, Madrid.

KUSSMAUL, Ann (1981): Servants in Husbandry in Early Modern England, Cambridge, Cambridge University Press.

LANA BERASAIN, José Miguel (2002): “Jornales, salarios, ingresos. Aproximación a la evolución de los niveles de vida desde la Navarra rural, 1801-1935", en MARTÍNEZ CARRIÓN, José Miguel (ed.), El nivel de vida en la España rural, siglos XVIII-XX, Alicante, Universidad de Alicante, pp. 183-233.

-(2005): "Aproximación a los salarios reales en la Navarra rural", en VIII Congreso de la Asociación Española de Historia Económica, Santiago de Compostela, 13-16 septiembre (http://www.usc.es/estaticos/congresos/histec05/a1_lana_berasain.pdf).

MALUQUER DE MOTES, Jordi (2005): "Consumo y precios", en CARRERAS, Albert, y TAFUNELL, Xavier (coords.), Estadísticas históricas de España: Siglos XIX-XX, Bilbao, Fundación BBVA, vol. III, pp. 1.247-1.296.

MARTÍNEZ CARRIÓN, José Miguel (ed.) (2002): El nivel de vida en la España rural, siglos XVIII-XX, Alicante, Universidad de Alicante.

MARTÍNEZ VARA, Tomás (1997): “Una estimación del coste de la vida en Santander, 1800-1860", Revista de Historia Económica, XV, 1, pp. 87-124.

MORENO LÁZARO, (2002): “ ¿Fomentó el capitalismo agrario la desigualdad? Salarios y niveles de vida en Castilla la Vieja, 1751-1861", en MARTÍNEZ CARRIÓN, José Miguel (ed.), El nivel de vida en la España rural, siglos XVIII-XX, Alicante, Universidad de Alicante, pp. 75-112.

—(2006): “El nivel de vida en la España atrasada entre 1800 y 1936. El caso de Palencia", Investigaciones de Historia Económica, 4, pp. 9-50.

MOSES, Gary (1999): "Proletarian labourers? East Riding farm servants, c.1850-75", Agricultural History Review, 47, 1, pp. 78-94.

PÉREZ CASTROVIEJO, Pedro (2006): “Poder adquisitivo y calidad de vida de los trabajadores vizcaínos, 1876-1936", Revista de Historia Industrial, 30, pp. 103-142.

ROCA FABREGAT, Pere (2005): “Quién trabajaba en las masías? Criados y criadas en la agricultura catalana (1670-1870)", Historia Agraria, 35, pp. 49-92.

SAGUER, Enric (2004): "Mossos i criats. Una radiografia del treball assalariat als masos (Girona, 1946)", Estudis d'Història Agrària, 17, pp. 813-827. 


\section{APÉNDICE 1}

ÍNDICES DE SALARIOS NOMINALES Y REALES EN NAVARRA, 1781-1936

(base $100=1891-1900$ )

\begin{tabular}{|c|c|c|c|c|c|c|c|c|}
\hline & (1) & (2) & (3) & (4) & (5) & (6) & (7) & (8) \\
\hline 1781 & - & - & 48,7 & 37,6 & - & - & - & - \\
\hline 1782 & 60,9 & - & 53,4 & 37,3 & - & 87,7 & 61,3 & - \\
\hline 1783 & 68,0 & - & 54,2 & 37,6 & 46,8 & 79,7 & 55,3 & 68,8 \\
\hline 1784 & 72,3 & - & 53,1 & - & 48,2 & 73,5 & - & 66,7 \\
\hline 1785 & 71,3 & - & 53,6 & - & 49,0 & 75,1 & - & 68,7 \\
\hline 1786 & 71,0 & - & 53,6 & - & 48,0 & 75,5 & - & 67,7 \\
\hline 1787 & 73,7 & - & 59,1 & - & 46,7 & 80,2 & - & 63,4 \\
\hline 1788 & 77,5 & - & 62,2 & - & 49,7 & 80,3 & - & 64,1 \\
\hline 1789 & 81,7 & - & 53,6 & - & 55,6 & 65,6 & - & 68,0 \\
\hline 1790 & 76,2 & - & 53,6 & - & 49,4 & 70,3 & - & 64,8 \\
\hline 1791 & 69,1 & - & 53,1 & - & 46,2 & 76,8 & - & 66,9 \\
\hline 1792 & 64,2 & - & 53,1 & - & 39,9 & 82,7 & - & 62,2 \\
\hline 1793 & 105,1 & - & 70,8 & - & 71,4 & 67,3 & - & 67,9 \\
\hline 1794 & 114,5 & - & 79,9 & - & 80,7 & 69,8 & - & 70,5 \\
\hline 1795 & 113,0 & - & 77,6 & - & 70,9 & 68,7 & - & 62,7 \\
\hline 1796 & 119,5 & - & 77,5 & 59,9 & 78,0 & 64,9 & 50,2 & 65,3 \\
\hline 1797 & 100,9 & - & 77,6 & - & 70,9 & 76,9 & - & 70,2 \\
\hline 1798 & 101,0 & - & 72,7 & - & 69,5 & 72,0 & - & 68,8 \\
\hline 1799 & 94,1 & - & 77,8 & - & 65,5 & 82,6 & - & 69,6 \\
\hline 1800 & 99,8 & - & 71,3 & 59,9 & 73,1 & 71,5 & 60,1 & 73,3 \\
\hline 1801 & 100,7 & - & 70,8 & 59,9 & 73,7 & 70,3 & 59,5 & 73,1 \\
\hline 1802 & 125,9 & - & 73,3 & 59,9 & 89,5 & 58,2 & 47,6 & 71,1 \\
\hline 1803 & 123,8 & - & 70,8 & 56,5 & 92,7 & 57,2 & 45,6 & 74,9 \\
\hline 1804 & 117,5 & - & 68,6 & 74,9 & 88,1 & 58,4 & 63,8 & 75,0 \\
\hline 1805 & 106,4 & - & 70,5 & 74,9 & 75,2 & 66,2 & 70,4 & 70,7 \\
\hline 1806 & 86,5 & - & 62,4 & 74,9 & 64,8 & 72,2 & 86,6 & 75,0 \\
\hline 1807 & 90,7 & - & 75,6 & 79,9 & 68,7 & 83,3 & 88,1 & 75,7 \\
\hline 1808 & 92,3 & - & 81,7 & 63,7 & 68,7 & 88,5 & 69,0 & 74,4 \\
\hline 1809 & 98,0 & - & 71,5 & 79,9 & 101,6 & 72,9 & 81,5 & 103,7 \\
\hline 1810 & 126,8 & - & 69,2 & 71,2 & - & 54,6 & 56,1 & - \\
\hline 1811 & 142,6 & - & 84,2 & 69,9 & - & 59,0 & 49,0 & - \\
\hline 1812 & 155,2 & - & 88,3 & 79,9 & - & 56,9 & 51,5 & - \\
\hline 1813 & 124,5 & - & 93,4 & 69,9 & - & 75,0 & 56,2 & - \\
\hline 1814 & 132,3 & - & 101,1 & 69,9 & - & 76,4 & 52,9 & - \\
\hline 1815 & 131,2 & - & 92,7 & 69,9 & 124,9 & 70,7 & 53,3 & 95,2 \\
\hline 1816 & 121,4 & - & 86,3 & 73,3 & 126,9 & 71,1 & 60,4 & 104,6 \\
\hline 1817 & 121,0 & - & 88,3 & 62,0 & 109,4 & 73,0 & 51,3 & 90,4 \\
\hline 1818 & 104,2 & - & 90,0 & 60,8 & 99,9 & 86,4 & 58,4 & 95,9 \\
\hline 1819 & 84,2 & - & 77,7 & 64,9 & 85,4 & 92,3 & 77,1 & 101,4 \\
\hline 1820 & 78,9 & - & 72,0 & 67,4 & - & 91,2 & 85,4 & - \\
\hline 1821 & 67,2 & - & 66,8 & 74,9 & - & 99,4 & 111,4 & - \\
\hline 1822 & 80,3 & - & 67,4 & 59,9 & - & 83,9 & 74,6 & - \\
\hline
\end{tabular}


APÉNDICE 1 (continuación)

ÍNDICES DE SALARIOS NOMINALES Y REALES EN NAVARRA, 1781-1936

$($ base $100=1891-1900)$

\begin{tabular}{|c|c|c|c|c|c|c|c|c|}
\hline & (1) & (2) & (3) & (4) & (5) & (6) & (7) & (8) \\
\hline 1823 & 87,0 & - & 69,8 & 69,9 & 94,1 & 80,3 & 80,4 & 108,3 \\
\hline 1824 & 87,0 & - & 71,9 & 67,4 & 96,8 & 82,6 & 77,5 & 111,2 \\
\hline 1825 & 78,2 & - & 69,7 & 60,0 & 84,4 & 89,1 & 76,7 & 108,0 \\
\hline 1826 & 71,3 & - & 68,4 & 51,6 & 81,4 & 95,9 & 72,4 & 114,1 \\
\hline 1827 & 67,3 & - & 69,8 & 55,9 & 80,1 & 103,7 & 83,1 & 119,0 \\
\hline 1828 & 70,6 & - & 67,2 & 51,5 & 81,8 & 95,1 & 73,0 & 115,9 \\
\hline 1829 & 61,2 & - & 62,5 & 53,8 & 77,8 & 102,1 & 88,0 & 127,2 \\
\hline 1830 & 64,6 & - & 66,6 & 52,6 & 77,5 & 103,1 & 81,4 & 119,9 \\
\hline 1831 & 64,3 & - & 64,1 & 50,9 & 78,7 & 99,7 & 79,2 & 122,4 \\
\hline 1832 & 64,2 & - & 61,1 & 43,2 & 80,0 & 95,2 & 67,3 & 124,7 \\
\hline 1833 & 61,6 & - & 51,5 & 44,9 & 79,0 & 83,7 & 72,9 & 128,3 \\
\hline 1834 & 71,5 & - & 55,1 & 56,0 & 80,1 & 77,0 & 78,3 & 111,9 \\
\hline 1835 & 94,7 & - & 57,8 & 56,7 & 80,1 & 61,0 & 59,9 & 84,7 \\
\hline 1836 & 93,7 & - & 69,8 & 57,5 & 79,9 & 74,5 & 61,4 & 85,3 \\
\hline 1837 & 94,1 & - & 67,9 & 64,9 & 80,1 & 72,1 & 69,0 & 85,1 \\
\hline 1838 & 100,0 & - & 80,0 & 73,7 & 79,9 & 80,0 & 73,7 & 79,9 \\
\hline 1839 & 75,3 & - & 74,0 & 73,6 & 80,2 & 98,2 & 97,7 & 106,5 \\
\hline 1840 & 65,2 & - & 69,0 & 71,6 & 79,8 & 105,8 & 109,8 & 122,3 \\
\hline 1841 & 73,4 & - & 70,5 & 63,3 & 79,9 & 96,0 & 86,2 & 108,9 \\
\hline 1842 & 81,5 & - & 68,4 & 58,3 & 79,9 & 83,9 & 71,5 & 98,0 \\
\hline 1843 & 75,6 & - & 69,9 & 63,3 & 79,9 & 92,4 & 83,6 & 105,6 \\
\hline 1844 & 69,2 & - & 69,3 & 59,9 & 79,9 & 100,1 & 86,6 & 115,5 \\
\hline 1845 & 66,0 & - & 70,9 & 62,4 & 79,8 & 107,4 & 94,5 & 120,8 \\
\hline 1846 & 69,4 & - & 70,4 & 62,4 & 85,8 & 101,4 & 89,9 & 123,5 \\
\hline 1847 & 83,6 & - & 70,2 & 63,7 & 80,0 & 83,9 & 76,2 & 95,7 \\
\hline 1848 & 68,0 & - & 69,5 & 67,4 & 79,8 & 102,2 & 99,2 & 117,4 \\
\hline 1849 & 65,4 & - & 66,9 & 67,4 & 79,7 & 102,3 & 103,2 & 121,9 \\
\hline 1850 & 66,4 & - & 67,8 & 63,7 & 79,8 & 102,1 & 95,9 & 120,2 \\
\hline 1851 & 73,3 & - & 65,3 & 59,9 & 79,8 & 89,0 & 81,7 & 108,9 \\
\hline 1852 & 68,7 & - & 66,4 & 66,2 & 79,8 & 96,8 & 96,4 & 116,1 \\
\hline 1853 & 73,6 & - & 67,0 & 68,7 & 79,7 & 90,9 & 93,3 & 108,3 \\
\hline 1854 & 80,2 & - & 67,2 & 74,9 & 79,8 & 83,7 & 93,4 & 99,5 \\
\hline 1855 & 81,7 & - & 69,8 & 77,4 & 79,8 & 85,4 & 94,7 & 97,7 \\
\hline 1856 & 104,0 & - & 82,9 & 88,7 & 80,0 & 79,7 & 85,3 & 77,0 \\
\hline 1857 & 106,5 & - & 91,1 & 84,9 & 79,9 & 85,6 & 79,7 & 75,0 \\
\hline 1858 & 89,3 & - & 93,9 & 76,2 & 78,0 & 105,1 & 85,3 & 87,4 \\
\hline 1859 & 94,7 & - & 86,3 & 88,9 & 80,5 & 91,2 & 93,8 & 85,0 \\
\hline 1860 & 99,3 & - & 89,0 & 106,7 & 85,0 & 89,6 & 107,4 & 85,6 \\
\hline 1861 & 104,4 & 96,1 & 92,3 & 92,9 & 79,7 & 88,4 & 89,0 & 76,3 \\
\hline 1862 & 98,6 & 96,8 & 97,9 & 99,4 & 81,5 & 99,3 & 100,8 & 82,7 \\
\hline 1863 & 95,7 & 91,4 & 101,4 & 96,2 & 87,2 & 106,1 & 100,5 & 91,2 \\
\hline 1864 & 91,2 & 89,6 & 94,1 & 97,4 & 91,1 & 103,2 & 106,8 & 100,0 \\
\hline
\end{tabular}


APÉNDICE 1 (continuación)

ÍNDICES DE SALARIOS NOMINALES Y REALES EN NAVARRA, 1781-1936

(base $100=1891-1900)$

\begin{tabular}{|c|c|c|c|c|c|c|c|c|}
\hline & (1) & (2) & (3) & (4) & (5) & (6) & (7) & (8) \\
\hline 1865 & 82,7 & 79,5 & 91,1 & 93,7 & 90,6 & 110,2 & 113,3 & 109,6 \\
\hline 1866 & 84,8 & 81,3 & 90,5 & 94,9 & 91,3 & 106,8 & 111,9 & 107,6 \\
\hline 1867 & 97,0 & 95,2 & 87,6 & 91,2 & 90,4 & 90,2 & 93,9 & 93,1 \\
\hline 1868 & 99,0 & 107,2 & 90,4 & 89,9 & 90,6 & 91,3 & 90,8 & 91,5 \\
\hline 1869 & 88,4 & 86,1 & 85,5 & 89,1 & 87,9 & 96,7 & 100,8 & 99,4 \\
\hline 1870 & 94,9 & 89,3 & 91,5 & 88,2 & 86,9 & 96,4 & 93,0 & 91,6 \\
\hline 1871 & 95,8 & 98,1 & 94,1 & 87,4 & 86,2 & 98,2 & 91,2 & 89,9 \\
\hline 1872 & 92,8 & 97,4 & 91,5 & 95,9 & 87,5 & 98,5 & 103,3 & 94,2 \\
\hline 1873 & 92,8 & 93,0 & 90,2 & 97,4 & 87,3 & 97,3 & 105,0 & 94,1 \\
\hline 1874 & 99,1 & 93,6 & 100,1 & 91,2 & 84,7 & 101,1 & 92,0 & 85,5 \\
\hline 1875 & 105,2 & 93,8 & 96,7 & 93,7 & 84,5 & 91,9 & 89,0 & 80,3 \\
\hline 1876 & 107,1 & 103,5 & 104,0 & 91,7 & 84,5 & 97,1 & 85,6 & 78,9 \\
\hline 1877 & 108,9 & 102,1 & 100,1 & 96,3 & 84,9 & 92,0 & 88,5 & 78,0 \\
\hline 1878 & 104,6 & 103,5 & 104,0 & 93,5 & 84,5 & 99,4 & 89,4 & 80,7 \\
\hline 1879 & 112,2 & 112,3 & 104,5 & 99,9 & 84,8 & 93,2 & 89,0 & 75,6 \\
\hline 1880 & 105,6 & 111,5 & 110,2 & 99,9 & 85,7 & 104,4 & 94,6 & 81,2 \\
\hline 1881 & 111,8 & 104,9 & 126,0 & 107,8 & 85,2 & 112,7 & 96,5 & 76,2 \\
\hline 1882 & 115,3 & 120,5 & 112,7 & 98,5 & 84,6 & 97,8 & 85,4 & 73,4 \\
\hline 1883 & 111,4 & 111,4 & 114,4 & 118,4 & 84,6 & 102,7 & 106,3 & 75,9 \\
\hline 1884 & 99,2 & 98,7 & 108,6 & 106,6 & 84,6 & 109,5 & 107,4 & 85,3 \\
\hline 1885 & 109,1 & 98,5 & 114,3 & 103,8 & 84,5 & 104,8 & 95,2 & 77,5 \\
\hline 1886 & 102,2 & 104,1 & 111,7 & 97,4 & 84,7 & 109,3 & 95,3 & 82,9 \\
\hline 1887 & 99,4 & 106,7 & 113,6 & 106,0 & 84,7 & 114,3 & 106,6 & 85,2 \\
\hline 1888 & 95,8 & 101,4 & 103,0 & 113,4 & 84,7 & 107,4 & 118,3 & 88,4 \\
\hline 1889 & 95,1 & 93,9 & 106,7 & 118,0 & 94,9 & 112,2 & 124,0 & 99,7 \\
\hline 1890 & 97,7 & 93,7 & 94,6 & 110,5 & 94,9 & 96,8 & 113,1 & 97,1 \\
\hline 1891 & 105,2 & - & 102,9 & 109,4 & 94,9 & 97,7 & 103,9 & 90,1 \\
\hline 1892 & 99,9 & - & 101,0 & 111,6 & 94,8 & 101,1 & 111,7 & 95,0 \\
\hline 1893 & 96,4 & - & 98,5 & 102,5 & 94,8 & 102,1 & 106,3 & 98,4 \\
\hline 1894 & 87,2 & - & 97,8 & 96,9 & 94,9 & 112,1 & 111,1 & 108,7 \\
\hline 1895 & 91,2 & - & 101,1 & 94,9 & 94,9 & 110,9 & 104,0 & 104,0 \\
\hline 1896 & 97,3 & - & 101,2 & 94,9 & 105,1 & 104,0 & 97,5 & 108,0 \\
\hline 1897 & 107,5 & - & 102,1 & 97,7 & 105,1 & 95,0 & 90,8 & 97,8 \\
\hline 1898 & 109,6 & - & 103,1 & 102,4 & 105,1 & 94,1 & 93,5 & 96,0 \\
\hline 1899 & 99,6 & - & 98,1 & 89,9 & 105,2 & 98,4 & 90,2 & 105,5 \\
\hline 1900 & 105,9 & - & 94,2 & 99,9 & 105,2 & 89,0 & 94,3 & 99,4 \\
\hline 1901 & 104,8 & - & 94,0 & - & 105,2 & 89,7 & - & 100,4 \\
\hline 1902 & 113,3 & - & 91,7 & - & 105,2 & 80,9 & - & 92,9 \\
\hline 1903 & 114,3 & - & 100,5 & - & 105,2 & 87,9 & - & 92,0 \\
\hline 1904 & 121,8 & - & 107,1 & 119,9 & 112,6 & 87,9 & 98,4 & 92,4 \\
\hline 1905 & 116,1 & - & 107,3 & 119,9 & 112,6 & 92,5 & 103,3 & 97,0 \\
\hline 1906 & - & - & 101,1 & 119,9 & 112,6 & - & - & - \\
\hline
\end{tabular}




\section{APÉNDICE 1 (continuación)}

ÍNDICES DE SALARIOS NOMINALES Y REALES EN NAVARRA, 1781-1936

(base $100=1891-1900)$

\begin{tabular}{rrrrrrrrr}
\hline & $\mathbf{( 1 )}$ & $\mathbf{( 2 )}$ & $\mathbf{( 3 )}$ & $\mathbf{( 4 )}$ & $\mathbf{( 5 )}$ & $\mathbf{( 6 )}$ & $\mathbf{( 7 )}$ & $\mathbf{( 8 )}$ \\
\hline $\mathbf{1 9 0 7}$ & - & 107,1 & 114,2 & 119,9 & - & 106,6 & 111,9 & - \\
$\mathbf{1 9 0 8}$ & - & 104,7 & 101,5 & 119,9 & - & 96,9 & 114,5 & - \\
$\mathbf{1 9 0 9}$ & - & 116,9 & 98,7 & 119,9 & - & 84,4 & 102,5 & - \\
$\mathbf{1 9 1 0}$ & - & 93,8 & 113,0 & 119,9 & - & 120,5 & 127,8 & - \\
$\mathbf{1 9 1 1}$ & - & 95,6 & 125,1 & 104,9 & 137,2 & 130,9 & 109,7 & 143,5 \\
$\mathbf{1 9 1 2}$ & - & 89,3 & 126,2 & 149,8 & 139,0 & 141,3 & 167,8 & 155,6 \\
$\mathbf{1 9 1 3}$ & - & 92,6 & 123,7 & 119,9 & 138,5 & 133,6 & 129,4 & 149,5 \\
$\mathbf{1 9 1 4}$ & - & 95,7 & 123,9 & 119,9 & 138,5 & 129,4 & 125,2 & 144,7 \\
$\mathbf{1 9 1 5}$ & - & 110,9 & 138,9 & 149,8 & 140,3 & 125,2 & 135,1 & 126,5 \\
$\mathbf{1 9 1 6}$ & - & 125,5 & 136,6 & 147,2 & 139,7 & 108,9 & 117,3 & 111,3 \\
$\mathbf{1 9 1 7}$ & - & 132,1 & 161,4 & 177,3 & 139,5 & 122,1 & 134,2 & 105,6 \\
$\mathbf{1 9 1 8}$ & - & 153,2 & 172,2 & 157,8 & 139,5 & 112,4 & 103,0 & 91,1 \\
$\mathbf{1 9 1 9}$ & - & 188,0 & 205,8 & 168,6 & 139,1 & 109,5 & 89,7 & 74,0 \\
$\mathbf{1 9 2 0}$ & - & 207,9 & 235,9 & 208,1 & - & 113,4 & 100,1 & - \\
$\mathbf{1 9 2 1}$ & - & 178,1 & 249,4 & 314,7 & - & 140,1 & 176,7 & - \\
$\mathbf{1 9 2 2}$ & - & 186,9 & 251,2 & 299,7 & 189,5 & 134,4 & 160,3 & 101,4 \\
$\mathbf{1 9 2 3}$ & - & 182,4 & 285,5 & 269,7 & 192,6 & 156,6 & 147,9 & 105,6 \\
$\mathbf{1 9 2 4}$ & - & 185,4 & 306,7 & 239,8 & 205,1 & 165,4 & 129,3 & 110,6 \\
$\mathbf{1 9 2 5}$ & - & 209,1 & 282,0 & 239,8 & 207,7 & 134,9 & 114,7 & 99,3 \\
$\mathbf{1 9 2 6}$ & - & 196,6 & 275,0 & 239,8 & 210,8 & 139,9 & 122,0 & 107,2 \\
$\mathbf{1 9 2 7}$ & - & 203,4 & 275,0 & 239,8 & 212,1 & 135,1 & 117,8 & 104,2 \\
$\mathbf{1 9 2 8}$ & - & 185,5 & 264,4 & 239,8 & 216,4 & 142,5 & 129,2 & 116,7 \\
$\mathbf{1 9 2 9}$ & - & 190,9 & 282,0 & 239,8 & 216,8 & 147,7 & 125,6 & 113,5 \\
$\mathbf{1 9 3 0}$ & - & 187,8 & 285,2 & 239,8 & 216,8 & 151,8 & 127,6 & 115,4 \\
$\mathbf{1 9 3 1}$ & - & 207,9 & 288,6 & 260,7 & 285,9 & 138,8 & 125,4 & 137,5 \\
$\mathbf{1 9 3 2}$ & - & 196,0 & 306,3 & 292,2 & 307,6 & 156,2 & 149,1 & 156,9 \\
$\mathbf{1 9 3 3}$ & - & 180,3 & 321,0 & 388,3 & 310,2 & 178,0 & 215,3 & 172,0 \\
$\mathbf{1 9 3 4}$ & - & 197,1 & 327,5 & 372,8 & 309,7 & 166,1 & 189,1 & 157,1 \\
$\mathbf{1 9 3 5}$ & - & 191,1 & 319,0 & - & 309,1 & 167,0 & - & 161,8 \\
$\mathbf{1 9 3 6}$ & - & 181,3 & 335,2 & 479,5 & 309,2 & 184,9 & 264,4 & 170,5 \\
& & & & & \\
\hline
\end{tabular}

(1) Índice del coste de la vida en Navarra con base 100 en 1891-1900.

(2) Índices del coste de la vida en Navarra de Ballesteros, ajustados con base 100 en 1891-1900.

(3) Índice del jornal masculino.

(4) Índice del jornal femenino.

(5) índice del salario del criado.

(6) Índice del salario real del jornalero [(3)/(1) ó (2) *100].

(7) Índice del salario real de la bracera [(4)/(1) ó (2) * 100].

(8) Índice del salario real del criado [(5)/(1) ó (2) * 100].

Fuentes: Las fuentes manuscritas citadas y Ballesteros (1997). 